\section{Ultrasonographic evaluation of patients with abnormal liver function tests in the emergency department}

\author{
Baran Umut Vardar', Carolyn S. Dupuis ${ }^{2}$, Alan J. Goldstein², Zeynep Vardar ${ }^{2}$, Young H. Kim² \\ 'Department of Radiology, Saint Vincent Hospital, Worcester, MA; '2Department of Radiology, \\ University of Massachusetts Medical School, Worcester, MA, USA
}

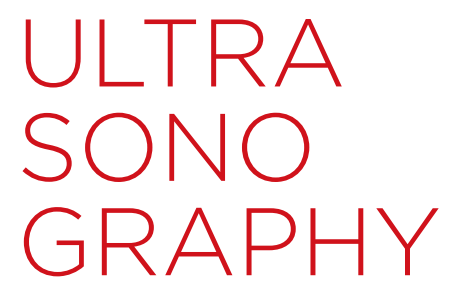

\section{REVIEW ARTICLE}

https://doi.org/10.14366/usg.21152 pISSN: 2288-5919 - elSSN: 2288-5943 Ultrasonography 2022;41:243-262

Received: July 27, 2021

Revised: November 12, 2021

Accepted: November 18, 2021

Correspondence to:

Young H. Kim, MD, PhD, Department of Radiology, University of Massachusetts Medical School, 55 N Lake Ave, Worcester, MA 01655, USA

Tel. +1-508-856-5740

Fax. +1-508-856-1860

E-mail:Young.Kim@umassmemorial. org

This is an Open Access article distributed under the terms of the Creative Commons Attribution NonCommercial License (http://creativecommons.org/ licenses/by-nc/4.0/) which permits unrestricted noncommercial use, distribution, and reproduction in any medium, provided the original work is properly cited.

Copyright (C) 2022 Korean Society of Ultrasound in Medicine (KSUM)

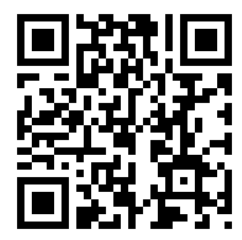

The liver biochemistry panel, also known as LFTs, typically consists of serum levels of aspartate aminotransferase (AST), alanine aminotransferase (ALT), alkaline phosphatase (ALP), gammaglutamyl transpeptidase (GGT), total bilirubin, direct bilirubin, prothrombin time (PT), and albumin. AST, ALT, ALP, and GGT are found within hepatocytes and biliary epithelial cells, and elevation of these enzymes suggests damage to the liver and/or biliary epithelial tissues. The total bilirubin level is the
How to cite this article:

Vardar BU, Dupuis CS, Goldstein AJ, Vardar Z, Kim YH. Ultrasonographic evaluation of patients with abnormal liver function tests in the emergency department. Ultrasonography. 2022 Apr;41(2):243-262. 
sum of indirect and direct bilirubin levels. Indirect (unconjugated) bilirubin is the waste product of heme metabolism, and it is taken up by the liver where it is converted to direct (conjugated) bilirubin and secreted into bile. Elevated direct bilirubin in association with increased ALP suggests bile flow obstruction [2]. PT and serum albumin levels are the only true hepatic function tests within the regularly used LFT panel that demonstrate the liver's synthetic function [3].

\section{The Role of US in Assessing Abnormal LFTs in the $\mathrm{ED}$}

US of the RUQ is the recommended initial diagnostic imaging examination in patients with signs and symptoms of hepatobiliary disease per the American College of Radiology Appropriateness Criteria and the most recent Tokyo Guidelines for acute cholecystitis
[4-6]. Using emergent US for patient triage is also recommended in patients with suspected hepatobiliary disease, including those with RUQ pain, and additional imaging can be obtained according to the US findings [4]. US is widely available, noninvasive, and relatively inexpensive; furthermore, it does not involve ionizing radiation. The sensitivity of US to detect acute cholecystitis was reported as $81 \%$, with $83 \%$ specificity, in a large meta-analysis [7]. US has been reported to have up to $95 \%$ sensitivity in detecting bile duct dilatation, $86 \%$ sensitivity in identifying the level of obstruction, and between $77 \%$ and $84 \%$ sensitivity in illustrating the obstructing cause [8-11].

The primary role of US is to identify the presence of biliary abnormalities (Fig. 1) [3]. If there is biliary ductal dilatation, the site and cause of the obstruction should be established. Biliary dilatation may be related to stones, primary biliary pathology, or secondary to extra-biliary disease. If there is no biliary duct dilatation, US can be

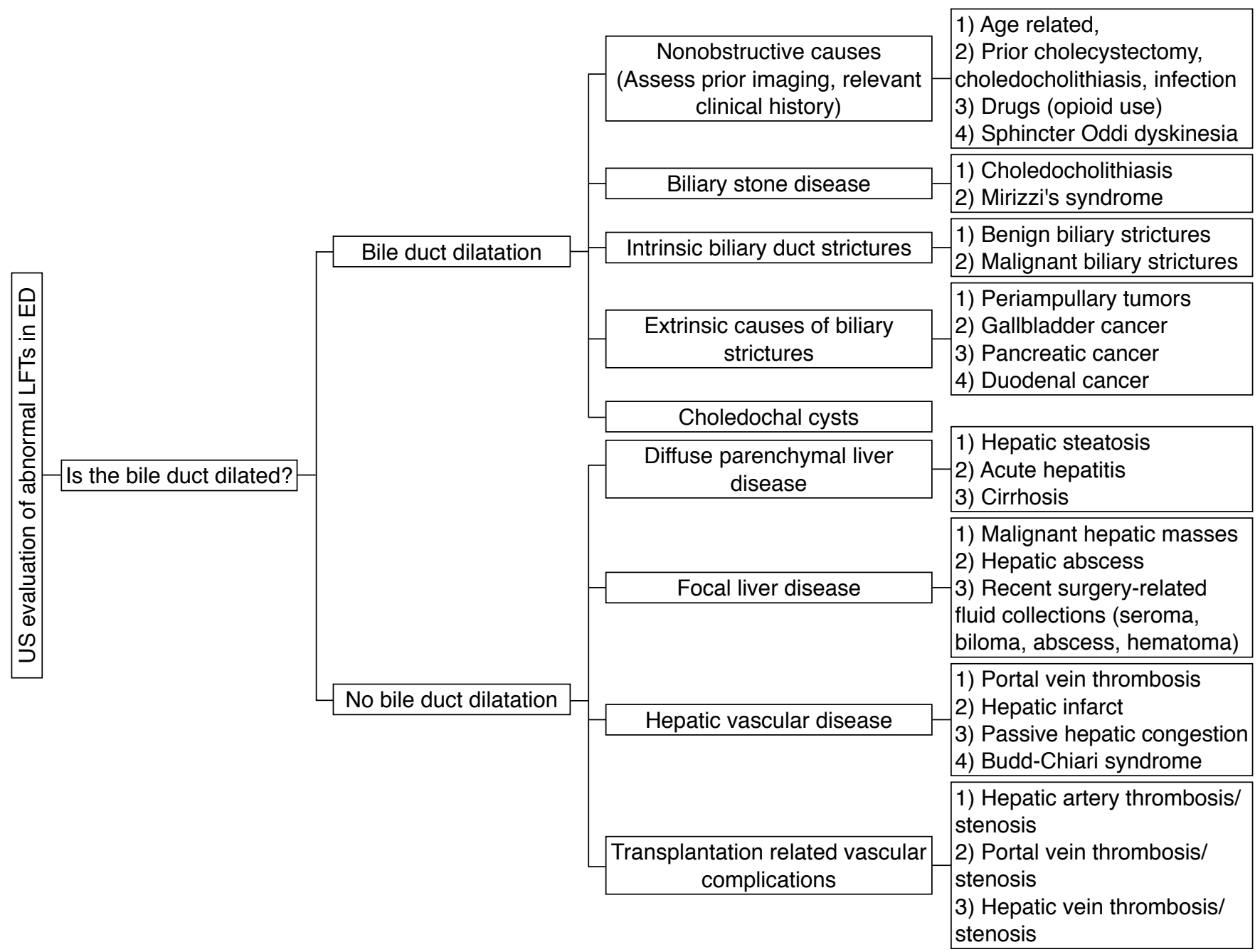

Fig. 1. Diagnostic approach and framework based on ultrasonography (US) for abnormal liver function tests (LFTs) in the emergency department (ED). 
useful for identifying hepatic processes that may cause abnormal LFTs. Diffuse liver parenchymal diseases, focal liver lesions, hepatic vascular abnormalities, transplantation-related vascular conditions, and postoperative complications may result in abnormal LFTs.

\section{US Technique}

The standard RUQ US protocol includes evaluation of the liver, intrahepatic and extrahepatic bile ducts, gallbladder, pancreas, inferior vena cava (IVC), and right kidney. A low-frequency (1-5 $\mathrm{MHz}$ ) curvilinear transducer is routinely used. Harmonic imaging has been shown to enhance the visualization of the biliary ducts and provide superior hepatobiliary image quality in obese patients $[12,13]$. Color Doppler imaging is typically applied to evaluate the patency and flow direction of the main portal vein, proper hepatic artery, and hepatic veins/IVC.

\section{Normal Biliary Anatomy on US and Determination of Biliary Duct Dilatation}

The major left and right hepatic ducts unite at the hepatic hilum and form the common hepatic duct (CHD). The cystic duct and CHD merge to form the common bile duct (CBD). The distal CBD courses through the pancreatic head and empties into the second portion of the duodenum at the ampulla of Vater. With US, the extrahepatic bile ducts are commonly referred to together as the common duct (CD) since the cystic duct insertion is usually not well visualized (Fig. 2).

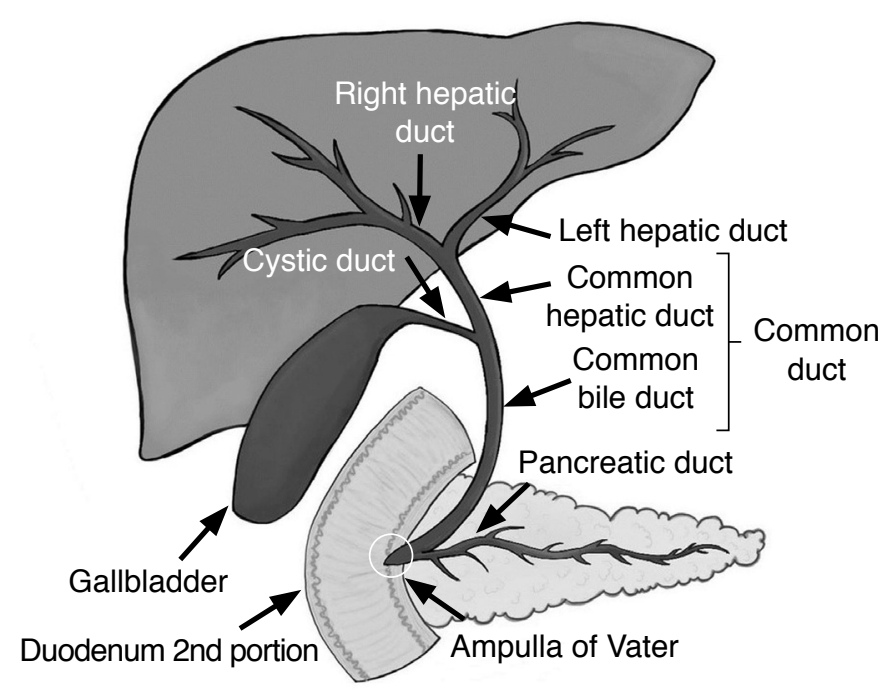

Fig. 2. Illustration of the biliary system. It is common to refer to the extrahepatic biliary ducts as the common duct, which comprises the common hepatic duct and common bile duct because the cystic duct insertion is usually not visualized on ultrasonography.
The level and etiology of the obstruction affect the pattern of biliary duct dilatation. Intrahepatic bile ducts are considered dilated if they are larger than $2 \mathrm{~mm}$ [14]. Dilated intrahepatic bile ducts run parallel to the portal veins and are known as the "parallel channel" sign or "double-barrel shotgun" sign [15,16] (Fig. 3).

Extrahepatic bile ducts are usually measured at the level of the mid-CD, caudal to the right hepatic artery. The distal CBD near the ampulla is often obscured due to artifacts from bowel gas in the adjacent stomach or duodenum. In general, a CD equal to or larger than $7 \mathrm{~mm}$ is considered abnormal and should be investigated to evaluate underlying causes of obstruction [17]. However, it should be noted that there are nonobstructive physiologic causes for a dilated CD, including advanced patient age, prior choledocholithiasis, prior cholecystectomy, prior sphincterotomy, previous cholangitis, medication (e.g., chronic opioid use), and sphincter of Oddi dyskinesia [18-20]. Although there are inconsistent reports about the relationship between bile duct diameter and aging, the upper limit of the CD in the elderly with an intact gallbladder is estimated to be up to $8.5-10 \mathrm{~mm}[21,22]$. In post-cholecystectomy patients, a CD dilatation up to $10 \mathrm{~mm}$ is considered normal in the absence of other evidence of biliary obstruction [19].

Gallbladder distention is often associated with bile duct obstruction. In the absence of other features of acute cholecystitis or known history of a prolonged fasting state, marked distention of the gallbladder may indicate that the cause of obstruction is either at or distal to the confluence of the cystic duct and CHD.

If available for review, prior imaging studies must be carefully assessed and compared to current imaging before making a determination about the acuity and clinical significance of bile duct dilatation.

\section{Conditions with Both Abnormal LFTs and Bile Duct Dilatation}

\section{Biliary Stone Disease \\ Choledocholithiasis}

Choledocholithiasis is the most common cause of biliary obstruction [23]. Patients usually present to the ED with RUQ pain. Laboratory analysis of LFTs typically reveals elevated serum ALP and direct bilirubin levels. Patients in whom superimposed acute cholangitis has developed may also present with fever and leukocytosis.

The sensitivity of transabdominal US to detect CBD stones is reported to be between $22 \%$ and $80 \%$ [11,24-26]. The typical sonographic finding is an echogenic, shadowing stone in the CBD with dilatation of the bile ducts proximal to the stone (Fig. 4). It should be noted that smaller stones $(<3 \mathrm{~mm})$ may not demonstrate acoustic shadowing and may appear only as a straight or curved 


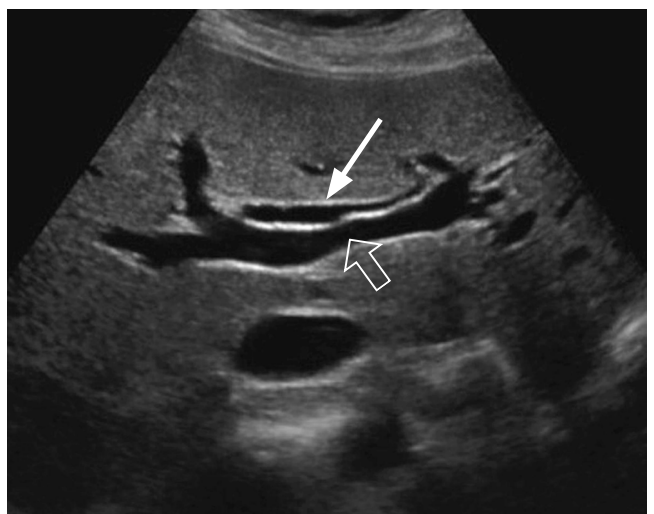

A

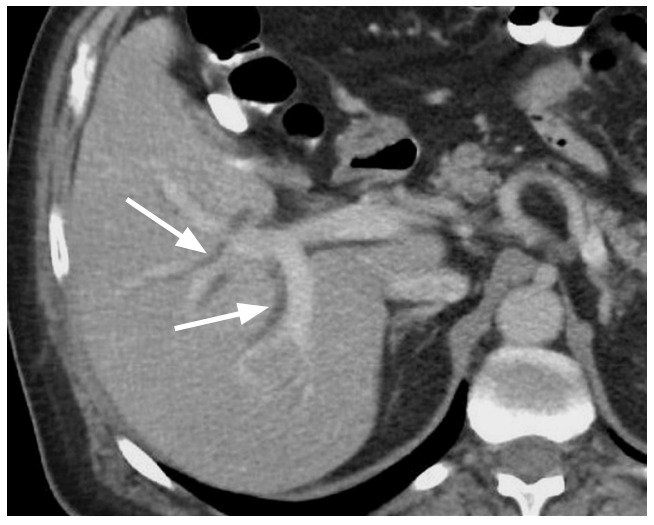

C

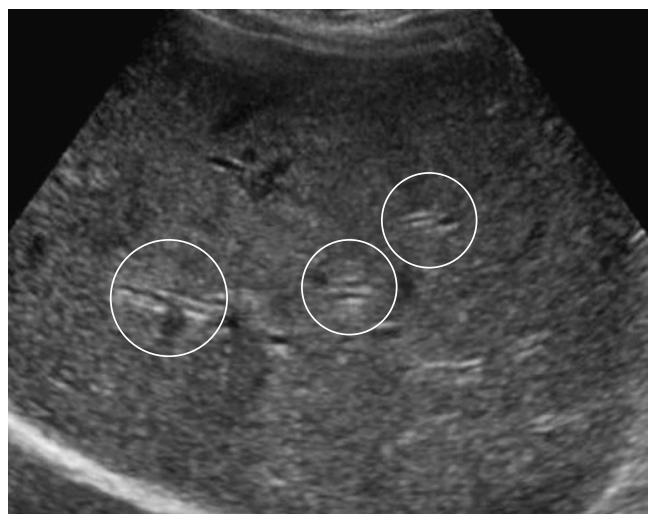

B

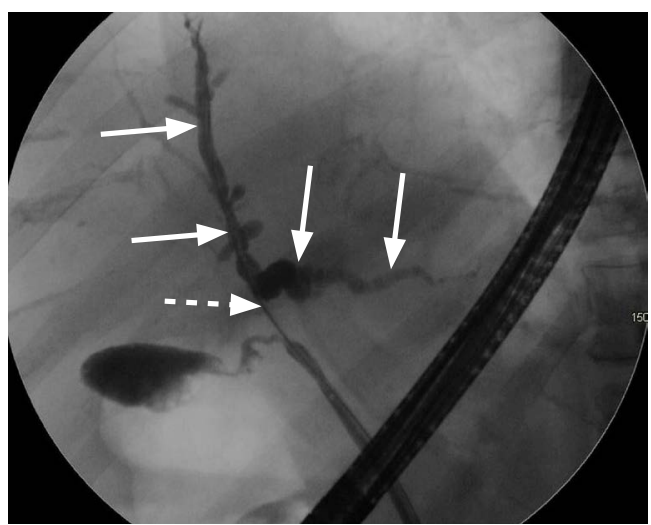

D

Fig. 3. Intrahepatic biliary ductal dilatation.

A. A 56-year-old woman presented with abdominal pain and abnormal liver function tests. Grayscale ultrasonography shows the "parallel channel" sign within the liver parenchyma that demonstrates the dilated intrahepatic bile ducts (arrow) adjacent to the portal vein branches (open arrow). B-D. A 71-year-old woman presented with right upper quadrant pain, jaundice, elevated liver enzymes, and direct bilirubin. Transverse grayscale ultrasonography (B) demonstrates the "parallel channel" sign that represents intrahepatic biliary ductal dilatation (circles). Contrast-enhanced axial computed tomography (C) shows diffuse intrahepatic biliary ductal dilation (arrows). Endoscopic retrograde cholangiopancreatography (D) shows dilated intrahepatic, right hepatic, and left hepatic ducts (arrows) with stenosis (dashed arrow) at the proximal common hepatic duct. The pathology was cholangiocarcinoma.

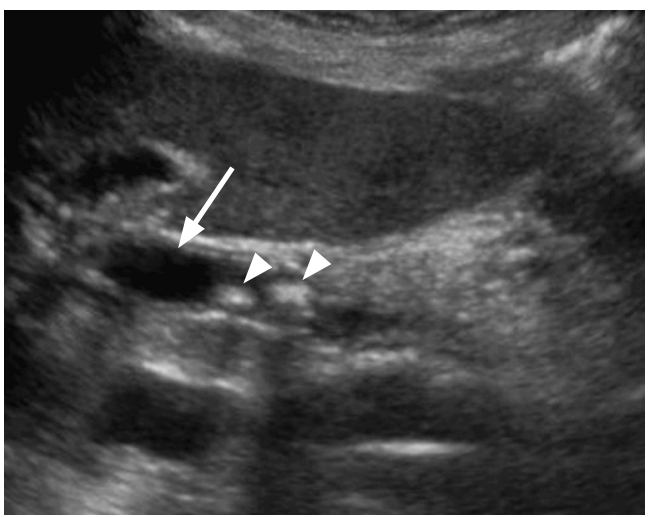

A

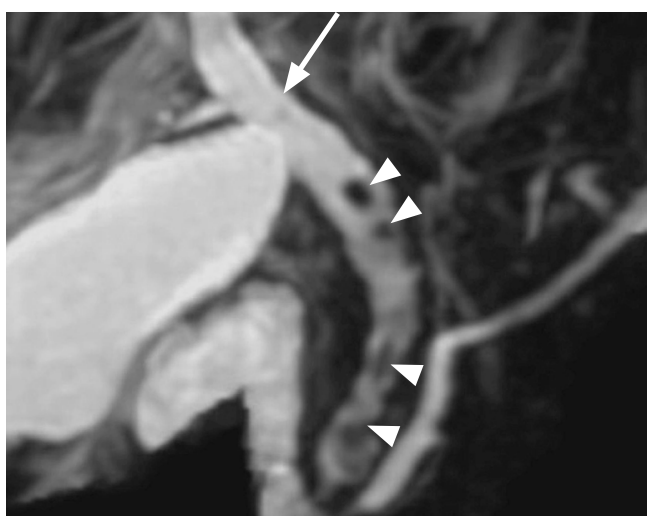

B

Fig. 4. Choledocholithiasis: a 91 -year-old woman with abdominal pain and abnormal liver function tests.

A. Grayscale ultrasonography of the liver demonstrates a dilated common bile duct (arrow). There are several common bile duct stones (arrowheads) with posterior shadowing. B. Coronal magnetic resonance cholangiopancreatography shows biliary ductal dilatation (arrow) and stones (arrowheads) throughout the common bile duct. 
echogenic focus within the duct (Fig. 5) [24,27]. The main limitations of CBD stone visualization are acoustic shadowing artifacts from overlying bowel gas. Changing the US window and the patient's positioning may help overcome these artifacts [17].

Smaller stones may not completely obstruct the bile duct and can present with a normal CBD diameter, especially in the early stages of choledocholithiasis [24,28]. Additionally, impacted small CBD stones may lack a fluid rim around them, making them even more difficult to appreciate [24]. Inspissated biliary sludge can also cause obstruction of the bile duct, but does not result in acoustic shadowing (Fig. 5). Magnetic resonance cholangiopancreatography is a useful adjunct in patients with clinically suspected choledocholithiasis in whom a stone is not identified on US $[29,30]$.

\section{Mirizzi syndrome}

Mirizzi syndrome is the phenomenon of an impacted gallstone in the cystic duct or gallbladder neck resulting in a mass effect on the adjacent CHD, leading to secondary biliary obstruction as evidenced by dilatation of the intrahepatic bile ducts (Fig. 6). The gallbladder is typically distended, and acute or chronic cholecystitis is a frequently associated condition.

\section{Intrinsic Biliary Duct Strictures}

Benign biliary strictures

Up to $30 \%$ of biliary strictures are benign, with the most common causes being primary sclerosing cholangitis, chronic pancreatitis, iatrogenic strictures, ampullary stenosis, lgG4-related cholangitis, and HIV cholangiopathy [31]. No US feature can reliably differentiate

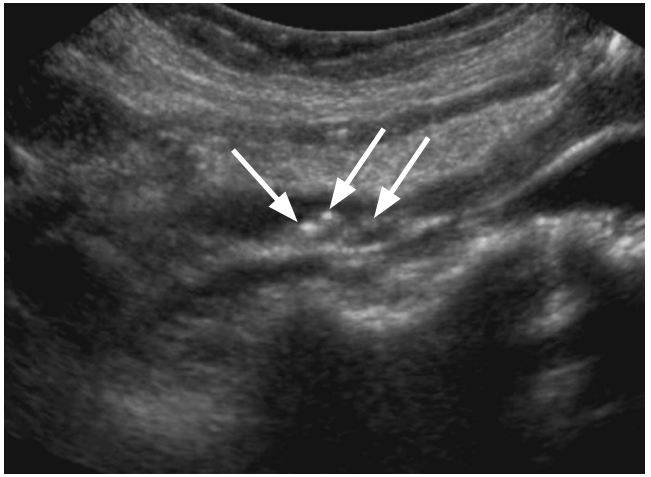

A

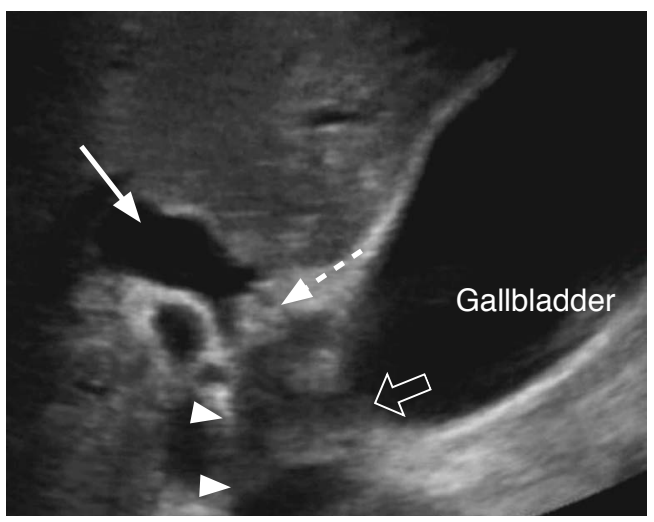

A

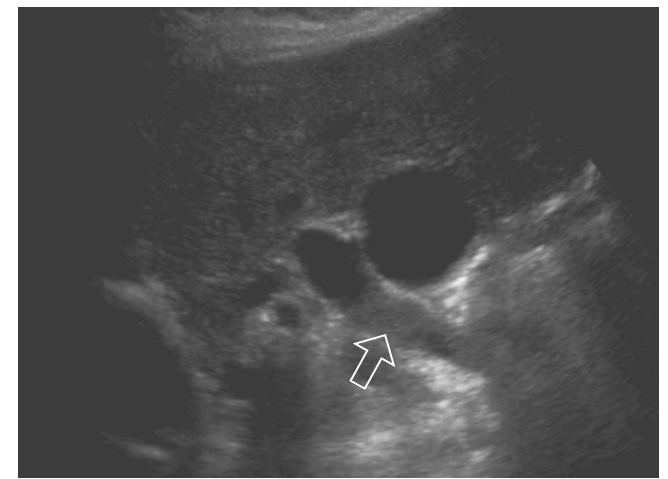

B

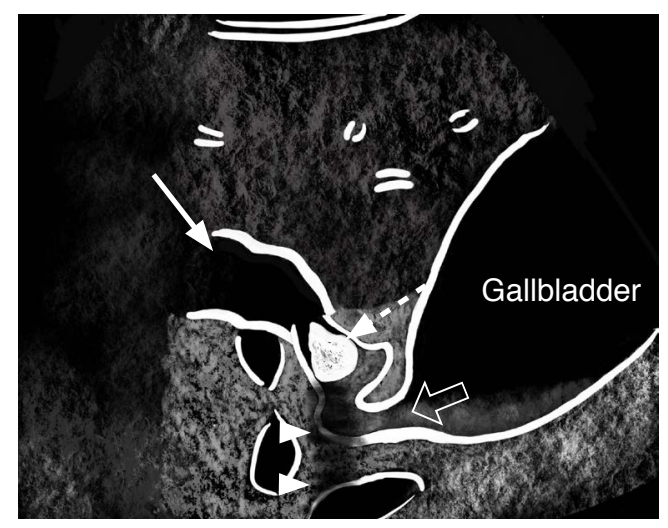

B
Fig. 5. Small biliary stones and biliary sludge.

A. A 61-year-old woman presented with right upper quadrant pain and abnormal liver function tests (LFTs). Grayscale ultrasonography shows small, non-shadowing stones (arrows) in the dilated common duct. B. A 73-year-old man presented with epigastric pain and abnormal LFTs. Grayscale ultrasonography demonstrates sludge (open arrow) in the common duct without posterior shadowing.

Fig. 6. Mirizzi syndrome: a 67-year-old man with jaundice, right upper quadrant pain, and elevated bilirubin and alkaline phosphatase levels.

A, B. Grayscale ultrasonography (A) and a corresponding schematic representation (B) reveal common hepatic duct dilatation (arrow) secondary to extrinsic compression from an impacted stone (dashed arrow) in the distal dilated cystic duct (open arrow). Sludge is noted in the dilated cystic duct. There is acoustic shadowing (arrowheads) posterior to the stone. The findings are in keeping with Mirizzi syndrome. 
between benign biliary strictures and malignant lesions (Fig. 7) [32]. However, depending on the etiology, the US findings of stricture may include short or long segments of irregular, circumferential bile duct wall thickening with multifocal sites of both narrowing and dilation [17].

\section{Malignant biliary strictures}

Any biliary dilatation secondary to bile duct strictures with jaundice should be considered malignant unless there is an apparent or known attributable benign etiology. Patients with malignant strictures may present to the ED with RUQ pain, jaundice, and pruritus. Elevations of total bilirubin, direct bilirubin, and ALP are common laboratory findings.

Cholangiocarcinoma is an adenocarcinoma of biliary epithelial cells, which is the most common cause of intrinsic malignant biliary stricture [33]. Cholangiocarcinoma can be classified into intrahepatic, perihilar, and extrahepatic disease [34]. Hilar cholangiocarcinoma is also known as a Klatskin tumor and is the most common type (70\%) [34]. Based on the macroscopic tumor growth pattern, cholangiocarcinoma can be classified into mass-forming, periductal infiltrating, and intraductal polypoid types. The bile ducts are usually dilated proximal to the lesion with abrupt narrowing at the mass or stricture site. Although US is not very specific in characterizing the mass, an ill-defined and mostly isoechoic mass can occasionally be observed in the mass-forming type. Bile duct thickening with shouldered margins is highly concerning for a malignant etiology, as may be seen in the periductal infiltrating type (Fig. 8).

\section{Extrinsic Causes of Biliary Strictures}

Periampullary tumors

Periampullary tumors include tumors of the ampulla of Vater, pancreas, and duodenum. Pancreatic adenocarcinoma is the most common type of periampullary tumor, resulting in obstruction of the distal CBD. These masses are typically hypoechoic and infiltrative tumors that arise from the pancreatic head and are generally hypovascular on color Doppler US. Often, simultaneous dilatation of the main pancreatic duct is seen (a.k.a. the double duct sign) (Fig. 9). Once a periampullary tumor is suspected on US, additional crosssectional imaging should be performed.

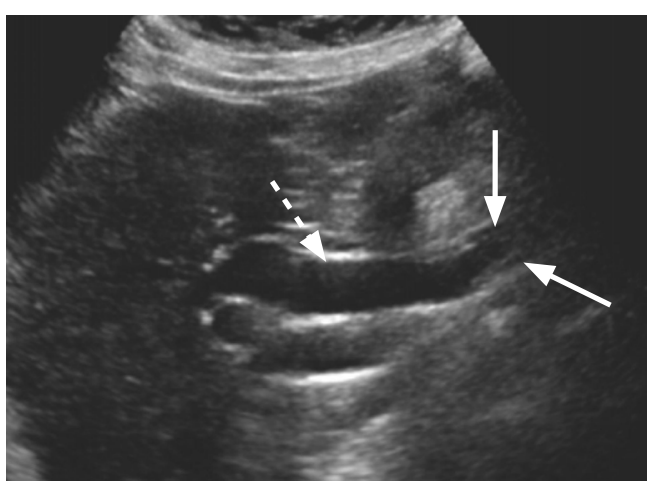

A

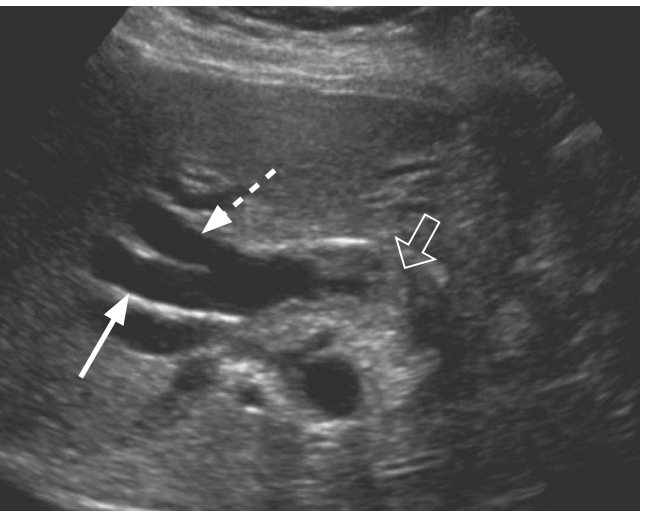

A

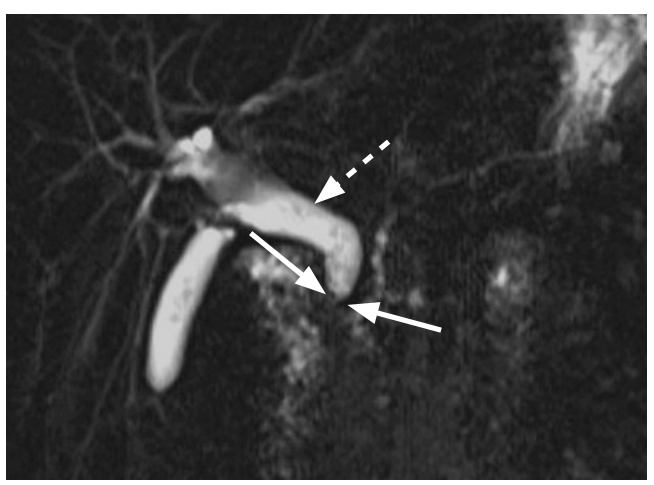

B

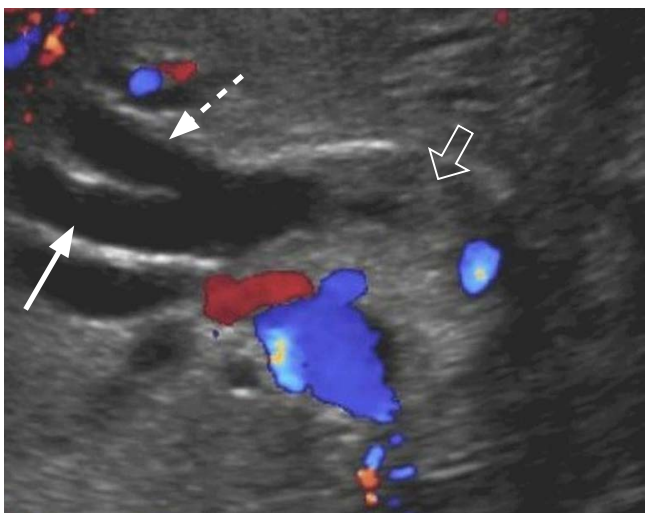

B
Fig. 7. Benign biliary stricture: a 67-year-old woman with subacute right upper quadrant abdominal pain and abnormal liver function tests.

A, B. Grayscale ultrasonography (A) and a coronal magnetic resonance cholangiopancreatography (B) demonstrate biliary duct dilatation (dashed arrows) proximal to a circumferential bile duct wall thickening in the distal common bile duct with narrowing (arrows). The pathology was a benign inflammatory stricture.

Fig. 8. Klatskin tumor: a 74-year-old woman with jaundice and elevated liver function tests.

A, B. Grayscale (A) and color Doppler (B) ultrasonography show marked dilatation of the right (arrows) and left hepatic ducts (dashed arrows) with an irregular mass (open arrows) in the common hepatic duct near the hilum. The biopsy was consistent with cholangiocarcinoma. 


\section{Gallbladder carcinoma}

Gallbladder adenocarcinoma is often asymptomatic until the advanced stages of the disease, and an initial presentation to the ED with jaundice is common. In its early stages, gallbladder carcinoma can present as a polypoid intraluminal mass or diffuse gallbladder wall thickening. However, the most common presentation is a large, ill-defined, heterogeneous, infiltrative mass replacing the gallbladder, often invading the adjacent liver and bile ducts, resulting in biliary obstruction, usually at the level of the hepatic hilum (Fig. 10).

\section{Choledochal Cysts}

A choledochal cyst is a rare congenital cystic dilatation of the biliary tree. Choledochal cysts are classified according to the Todani classification, and the most common type is type I, which involves the complete or focal dilatation of the CBD and accounts for $80 \%-90 \%$ of cases [35]. This diagnosis is often made in the pediatric age group and is often incidentally found in asymptomatic patients [36]. Pain, nausea, vomiting, jaundice, and fever are more common symptoms in adults. Type I choledochal cysts appear on US as an anechoic fusiform or saccular dilatation of the CBD (Fig. 11) [36]. A careful assessment for an intraluminal stone and mass (cholangiocarcinoma) should be performed since their incidence is increased in patients with type I choledochal cyst [36].

\section{US Findings in the Setting of Abnormal LFTs without Bile Duct Dilatation}

\section{Diffuse Parenchymal Liver Disease}

Hepatic steatosis

Steatosis is the most common diffuse liver abnormality, with alcohol abuse and nonalcoholic fatty liver disease being the most common causes [37]. Most patients in the ED are diagnosed with imaging done for abnormal LFTs or incidentally when imaged for other conditions $[38,39]$. Typically, levels of liver aminotransferases (AST and ALT) are increased [39]. On US, the hepatic parenchyma demonstrates increased echogenicity with mild coarsening, often resulting in increased sound beam attenuation and poor penetration (Fig. 12) [40]. Hepatic fat deposition can be diffuse, focal, multifocal, or geographic. It can mimic a hepatic mass. The absence of parenchymal distortion and a mass effect on vessels are important findings to help distinguish focal hepatic steatosis or areas of fatty sparing from an actual liver mass.

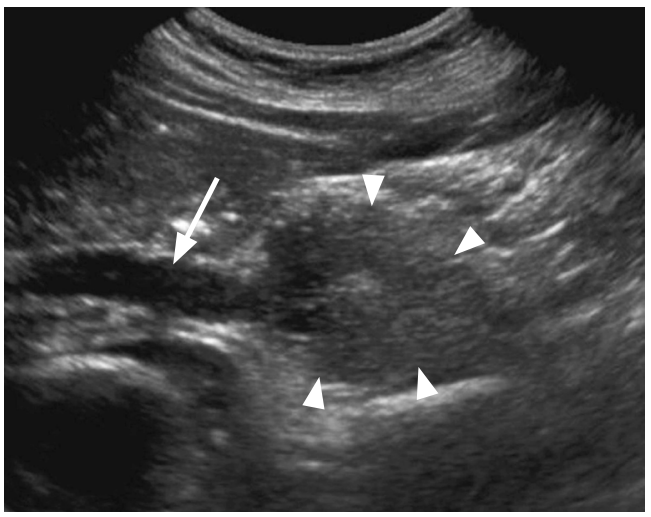

A

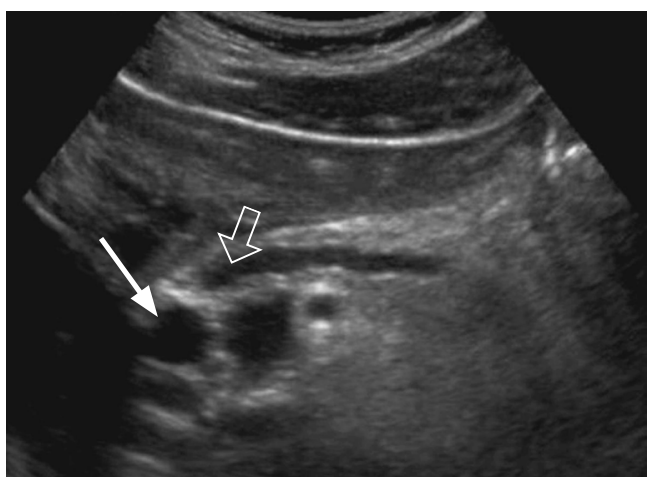

C

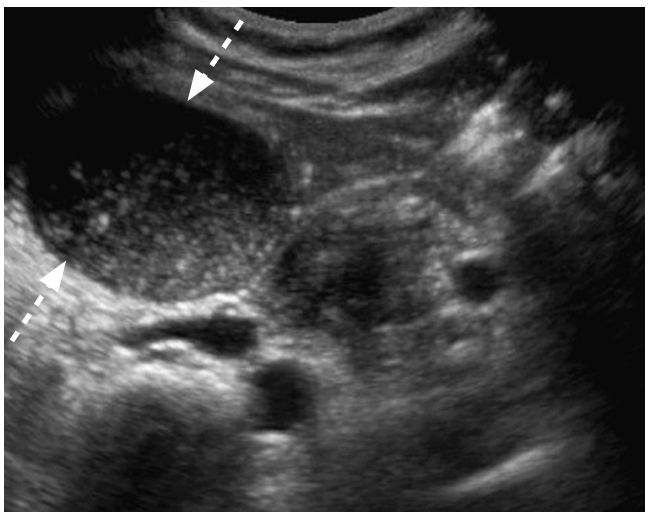

B

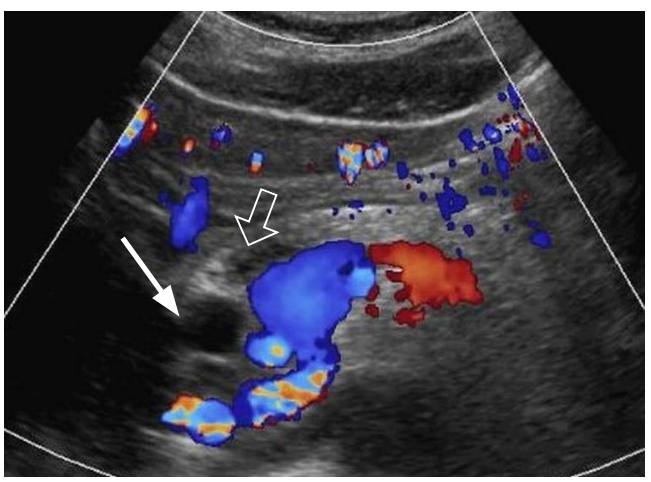

D
Fig. 9. Periampullary tumor: a 41 -year-old man with a 2-week history of epigastric pain, nausea, and mildly elevated liver enzymes and lipase.

Grayscale $(A-C)$ and color Doppler (D) ultrasonography are shown. A. There is a large, heterogeneous, hypoechoic mass lesion (arrowheads) at the head of the pancreas causing bile duct dilatation (arrow). B. The gallbladder is filled with sludge and distended (dashed arrows). C, D. Simultaneous dilatation of the common bile duct (arrows) and pancreatic duct (open arrows) due to the pancreatic head mass (double duct sign) is shown. The pathology was neuroendocrine tumor. 


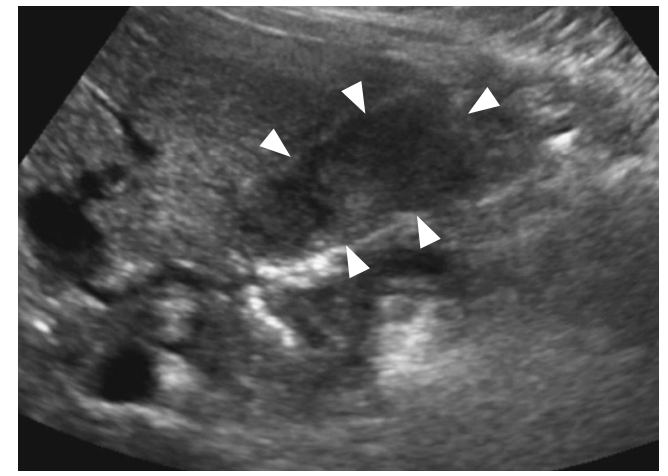

A

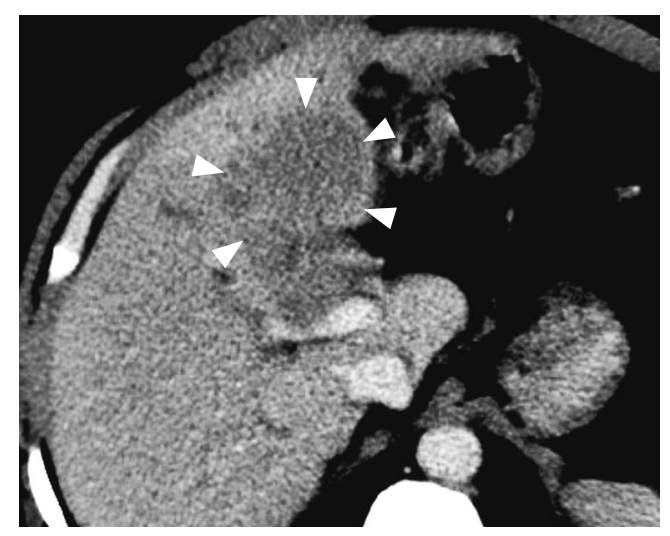

C

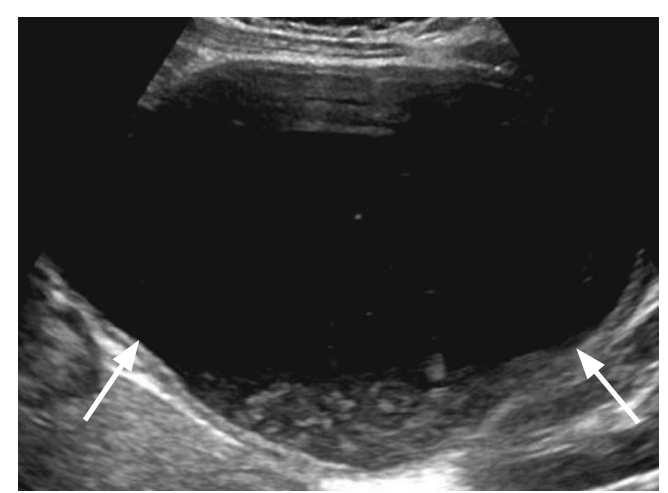

A

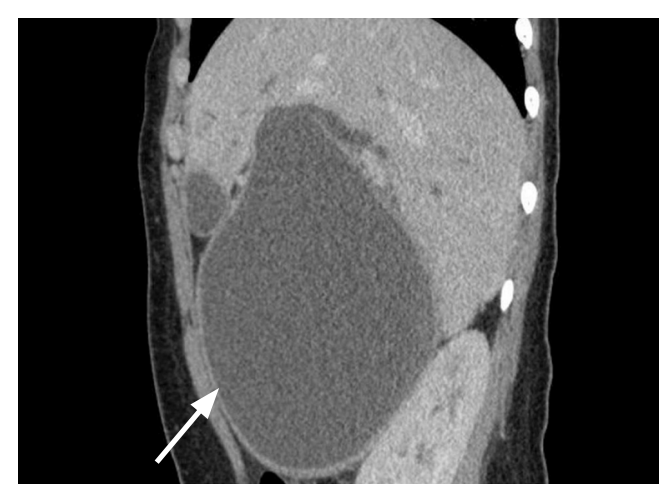

C

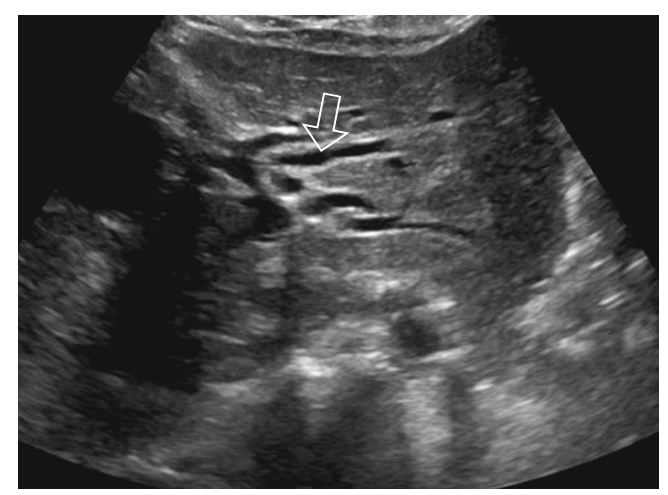

B

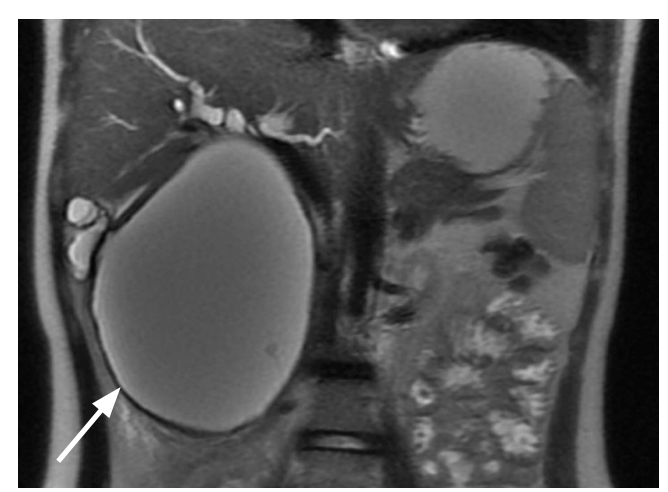

D

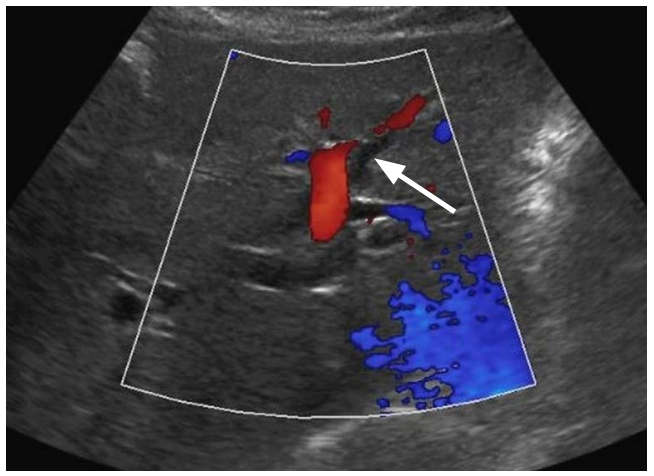

B

Fig. 10. Gallbladder carcinoma: a 72-year-old woman with a 3-week history of right upper quadrant pain and jaundice presented to the emergency department with abnormal liver function tests.

A, B. Grayscale (A) and color Doppler (B) ultrasonography show a large hypoechoic mass (arrowheads) in the gallbladder fossa with dilated intrahepatic biliary ducts (arrow). C. Contrast-enhanced axial computed tomography demonstrates a heterogeneous mass (arrowheads) in the gallbladder fossa with extension into the hilum causing adjacent bile duct dilatation.

Fig. 11. Type I choledochal cyst: a 17 -year-old male patient with jaundice, abdominal pain, and abnormal liver function tests.

A. Grayscale ultrasonography shows marked fusiform dilatation of extrahepatic bile ducts containing dependent echogenic bile sludge, which mimics an anechoic cystic mass on ultrasonography (arrows). B. There is moderate dilatation of intrahepatic biliary ducts in the left lobe of the liver (open arrow). C, D. Contrastenhanced sagittal computed tomography (C) and coronal T2weighted magnetic resonance (D) redemonstrate fusiform cystic dilatation (arrows) of the common bile duct, consistent with a type I choledochal cyst. 


\section{Acute hepatitis}

The most common etiologies of acute hepatitis are viral (hepatitis A, B, C, D, E, cytomegalovirus, Epstein-Barr virus) and drug-related (e.g., acetaminophen). Liver enzymes are generally markedly elevated. The US findings of acute hepatitis are not always specific, and normal US does not exclude the diagnosis. However, the echogenicity of the liver parenchyma may be diffusely decreased, causing the normal periportal fat to appear relatively hyperechoic, resulting in the so-called "starry sky" appearance. Unfortunately, the sensitivity and specificity of this finding have been found to be poor [41]. Hepatomegaly, gallbladder wall edema, and reactive

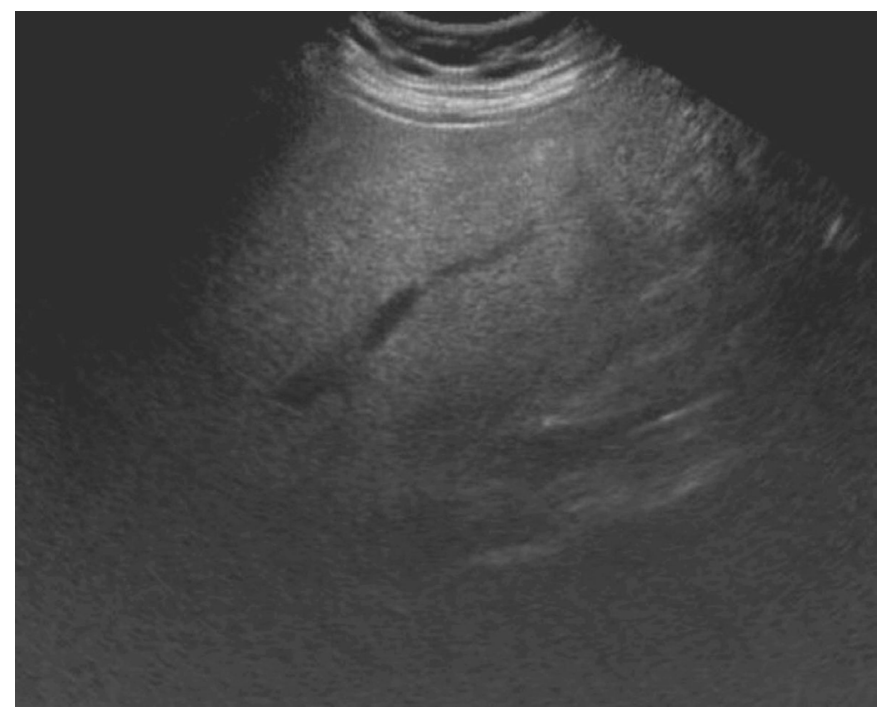

Fig. 12. Hepatic steatosis: a 56-year-old man with the characteristic appearance of grade III hepatic steatosis lacks periportal and diaphragmatic echogenicity and poor visualization of deep portions of the liver due to increased parenchymal attenuation on ultrasonography. lymphadenopathy in the porta hepatis may also be seen (Fig. 13).

\section{Cirrhosis}

Cirrhosis is the end result of several forms of chronic liver disease that eventually result in nodular regeneration and fibrosis. The most common causes are alcohol abuse, nonalcoholic steatohepatitis, and chronic viral hepatitis (hepatitis B and C). Liver enzymes are generally increased initially, and bilirubin levels may increase with the progression of cirrhosis. On US, the echotexture of the liver parenchyma becomes coarsened and heterogeneous with capsular surface nodularity (Fig. 14). If portal hypertension develops, the portal vein diameter may increase $(>13 \mathrm{~mm})$, with slow or reversed flow on Doppler imaging [42]. Portosystemic collaterals often develop, and paraumbilical veins may dilate.

\section{Focal Liver Abnormalities \\ Malignant hepatic masses}

Metastases are by far the most common malignant liver lesions. Elevated liver enzymes are often seen in patients with extensive liver metastasis. Hepatic metastases can have a variable appearance depending on the primary tumor type. Metastases are typically multifocal, each demonstrating a similar appearance on US. Although usually solid, they can also appear mixed cystic and solid, cystic, partially calcified, or infiltrative. Central necrosis may be observed, especially with rapidly growing tumors. The "target" or "bullseye" signs can be seen in large lesions due to central necrosis (Fig. 15). The vascularity of metastases is variable and depends largely on the primary tumor type.

Hepatocellular carcinoma (HCC) is the most common primary liver malignancy, and it is most common in patients with underlying cirrhosis. Rapid deterioration of liver function in a patient with known cirrhosis may be seen with the development of HCC. Only

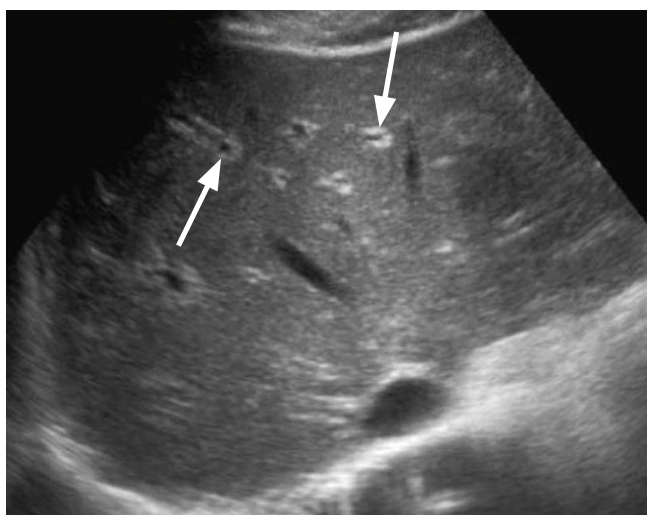

A

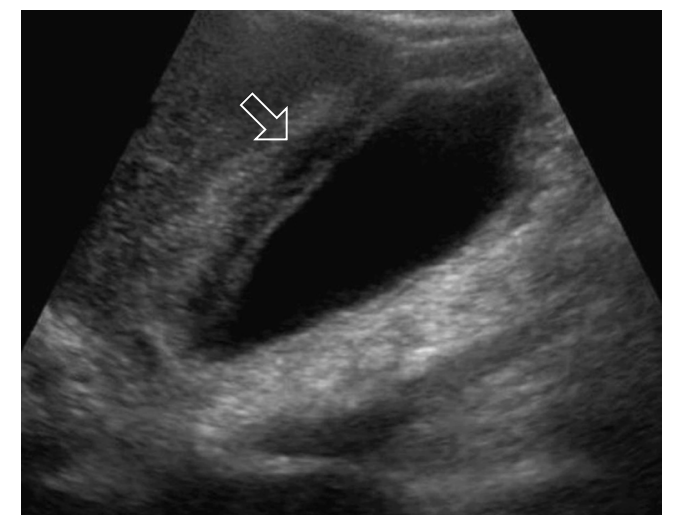

B

Fig. 13. Acute hepatitis: a 24-year-old man with right upper quadrant pain, jaundice, nausea, and abnormal liver function tests.

Grayscale ultrasonography shows the findings of acute hepatitis. A. Decreased hepatic echogenicity and accentuated brightness of the portal triads and portal vein walls (arrows), consistent with a starry sky appearance. $B$. There is reactive diffuse gallbladder wall thickening/ edema (open arrow). 
around $20 \%$ of HCC cases occur in non-cirrhotic livers. This can be seen in patients with chronic hepatitis B or C [43]. HCC may be focal, multifocal, or infiltrative. A hypoechoic peripheral halo may be visible around the periphery of an HCC lesion, which may help differentiate HCC from background regenerative and dysplastic

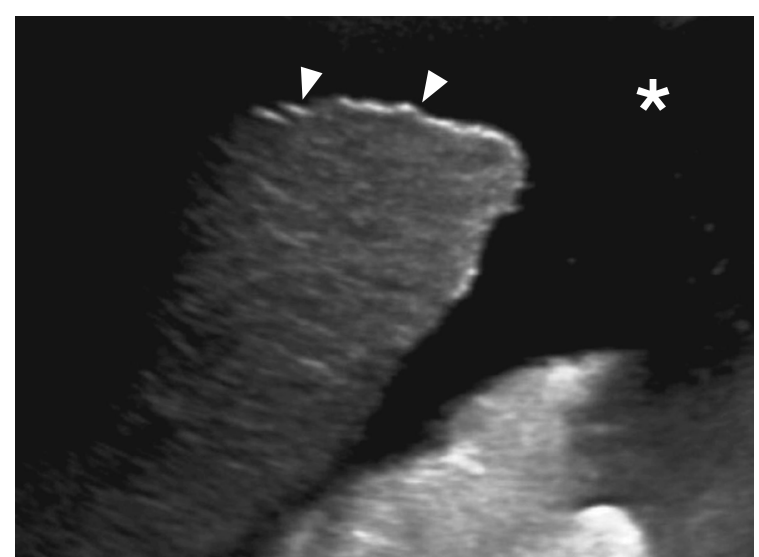

Fig. 14. Cirrhosis: a 72-year-old man presented to the emergency department with swelling of the abdomen and was found to have elevated liver function tests. Transverse grayscale ultrasonography shows surface nodularity (arrowheads), coarsened hepatic echotexture, and large ascites (asterisk). nodules (Fig. 15). Portal vein thrombosis (PVT) may be an important accompanying feature, especially in the infiltrative subtype, which is sometimes the only demonstrable finding on US.

Intrahepatic cholangiocarcinoma (ICC) is the second most common primary hepatic malignancy [44]. ICC often appears as a heterogeneous, echogenic mass. Although not a specific finding, capsular retraction and peripheral bile duct dilatation can help distinguish it from other tumors (Fig. 15).

\section{Hepatic abscess}

The spread of infection can occur hematogenously from an abdominal source, directly ascend the biliary tree, or result from direct inoculation of the liver from trauma or an invasive procedure. Abscesses are typically seen as rounded, irregular, and thick-walled fluid collections (Fig. 16). In severe cases, several communicating collections spreading throughout the different hepatic segments with peripheral heterogeneous phlegmonous regions can be observed. The US appearance of hepatic abscesses is variable, ranging from cystic to a heterogeneous, echogenic, solid mass-like lesion, depending on the degree of abscess maturation (Fig. 16). Due to these diverse US appearances, clinical information is essential for a correct diagnosis.

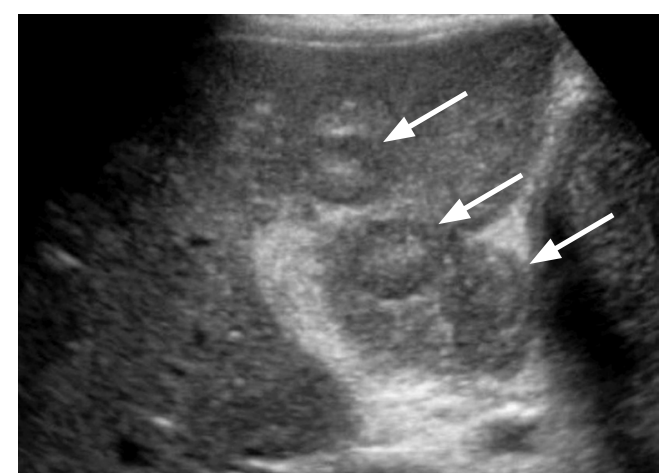

A

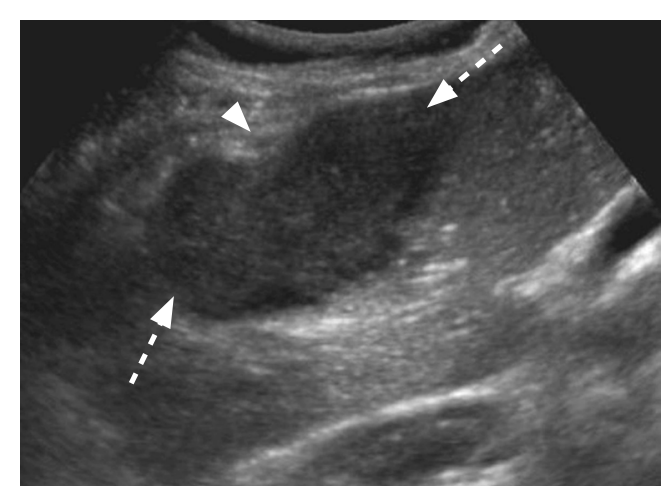

C

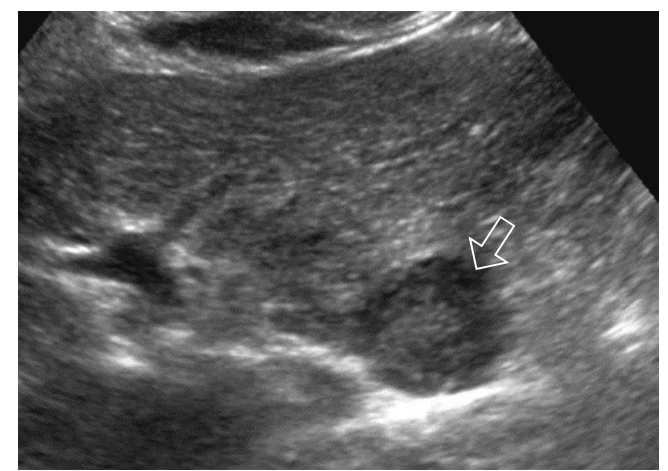

B

Fig. 15. Malignant hepatic lesions.

A. A 73-year-old woman presented with jaundice, abdominal pain, and abnormal liver function tests. Grayscale ultrasonography reveals multiple hypoechoic masses (arrows) with a target or bullseye sign. These features are suspicious for metastases. B. A 35-yearold man with known hepatitis B presented with abdominal pain and mildly elevated liver function tests (LFTs). Grayscale ultrasonography shows a hypoechoic mass (open arrow) in segment 2 with background coarsened hepatic echotexture. Subsequently obtained contrast-enhanced computed tomography (not shown) confirmed the diagnosis of hepatocellular carcinoma. C. Grayscale ultrasonography shows a large peripheral hypoechoic mass (dashed arrows) with associated capsular retraction (arrowhead). The biopsy was consistent with intrahepatic cholangiocarcinoma. 


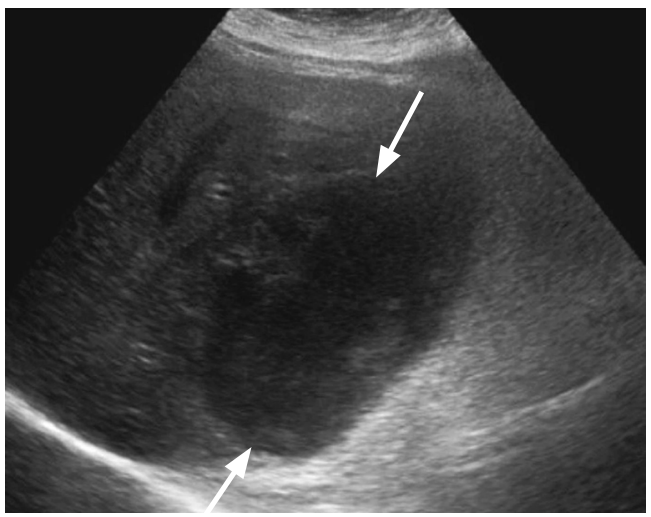

A

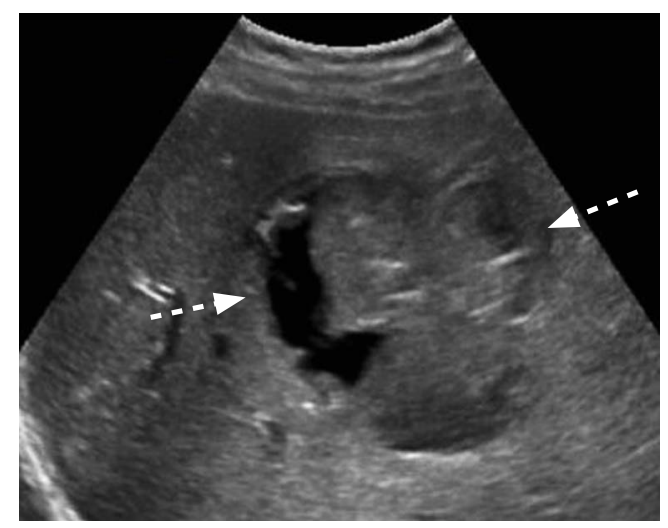

C

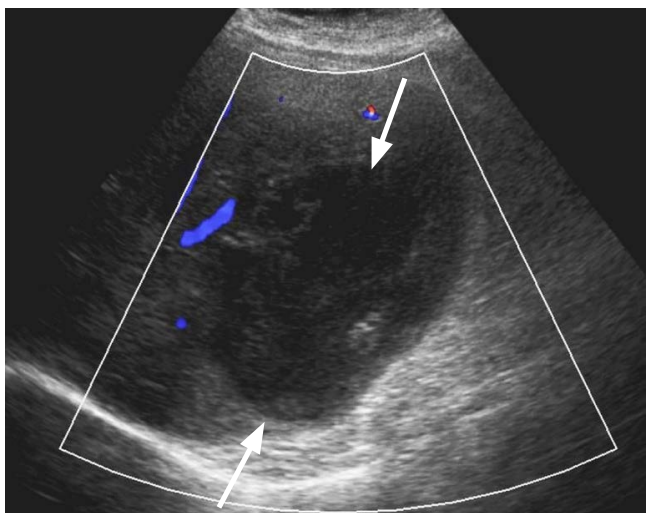

B

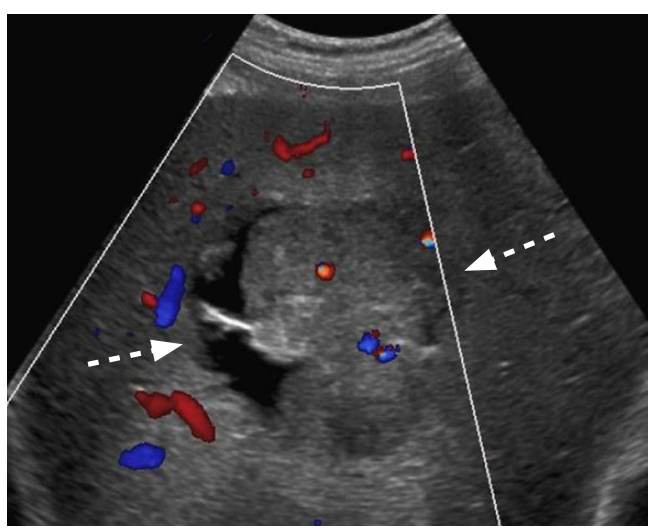

D
Fig. 16. Hepatic abscesses.

A, B. A 59-year-old man presented with fever, right upper quadrant pain, abnormal liver function tests, and leukocytosis. Grayscale (A) and color Doppler (B) ultrasonography show a hypoechoic lesion (arrows) with heterogeneous internal echoes in the liver without internal vascularity, suggestive of a liquified abscess. C, D. A 60-year-old man presented with right upper quadrant pain, abnormal liver function tests, and leukocytosis. Grayscale (C) and color Doppler (D) ultrasonography show a complex solid and cystic mass (dashed arrows) in the liver parenchyma with mild internal vascularity suggestive of a partially liquified abscess.

\section{Recent surgery-related fluid collections}

Postoperative perihepatic fluid collections, including seromas, bilomas, hematomas, and abscesses, may cause abnormal LFTs, and the initial differential diagnosis can be suggested with US [45]. Seromas are serous fluid collections that occasionally occur after surgery. Bilomas are bile collections most commonly develop after an iatrogenic injury to the biliary tree, resulting in bile leak. They both appear as anechoic simple fluid collections with posterior acoustic enhancement, and they are indistinguishable by US. Hepatobiliary scintigraphy may help diagnose bilomas by demonstrating radiotracer accumulation outside the biliary tree (Fig. 17). Hematomas are typically found during the early postoperative period and may vary from an anechoic cystic collection to heterogeneous echogenic mass-like lesion depending on the acuity of the hematoma (Fig. 17). Secondary infection of any of the above post-surgical collections results in an abscess (Fig. 17).

Whenever a newly developed intrahepatic cystic lesion is identified in a postoperative patient, a hepatic arterial pseudoaneurysm should be considered. This is especially true if it is located adjacent to a known vascular anastomosis. Pseudoaneurysms appear as anechoic cystic structures on grayscale US and have a typical "yin-yang" appearance on color Doppler imaging.

\section{Hepatic Vascular Abnormalities}

Portal vein thrombosis

PVT most commonly occurs in patients with cirrhosis or with underlying prothrombotic conditions. Although it can be clinically silent, patients often present to the ED with acute abdominal pain. Color Doppler shows no luminal flow in complete acute thrombosis, whereas non-occlusive PVT appears as a luminal filling defect. An acute thrombus generally appears expansile and either isoechoic or hypoechoic. With progressive chronicity, a thrombus may gradually appear more eccentric within the lumen and increasingly hyperechoic $[46,47]$. Color Doppler is also useful to differentiate a tumor thrombus from a bland thrombus by demonstrating internal arterial flow within a tumor thrombus (Fig. 18). In contrast, a bland thrombus is completely avascular (Fig. 19). Additionally, a tumor thrombus generally appears more expansile than a bland thrombus [48].

\section{Hepatic infarct}

Hepatic infarct occurs due to acute hepatic hypoperfusion secondary to systemic hypotension or hepatic artery occlusion from thrombosis 


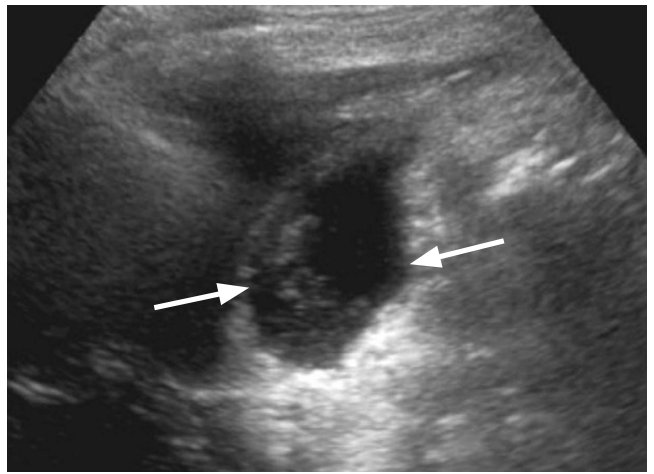

A

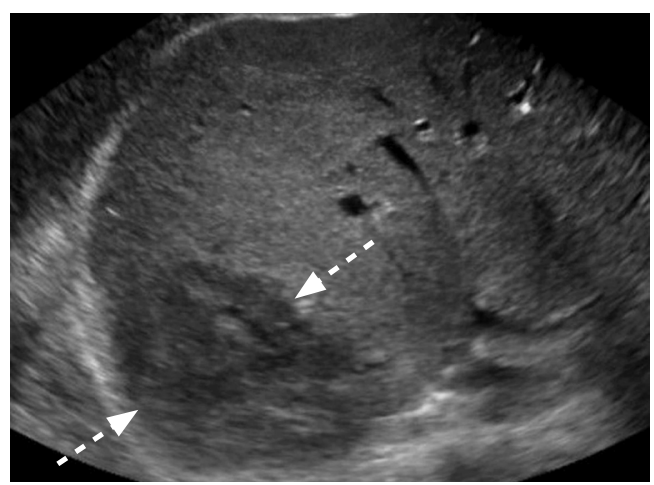

C

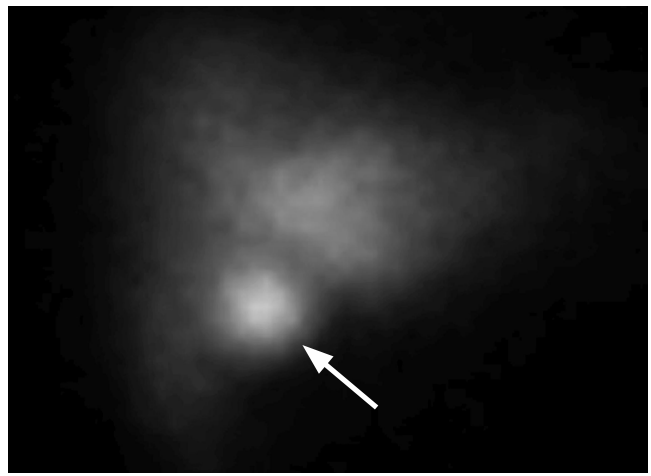

B

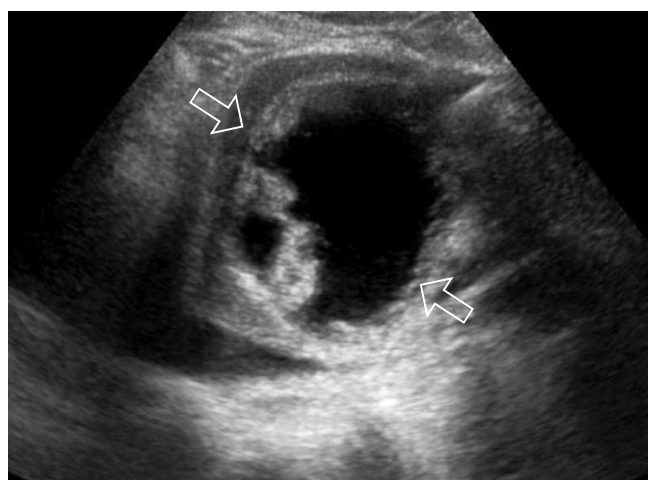

D

Fig. 17. Recent surgery-related fluid collections.

A, B. A 76-year-old woman presented with persistent right upper quadrant abdominal pain after cholecystectomy 1 week previously. Grayscale ultrasonography (A) shows a fluid collection with internal debris in the gallbladder fossa (arrows). Cholescintigraphy scan (B) shows increased activity (arrow) in the gallbladder fossa, consistent with a biloma, which was confirmed via drainage. C. A 45-year-old woman presented with abdominal pain and fatigue 1 week after cholecystectomy. Grayscale ultrasonography shows a large, hypoechoic, heterogeneous collection (dashed arrows) along the right lobe of the liver, consistent with a hematoma. D. A 63-year-old woman presented with abdominal pain, fever, and abnormal liver function tests 4 weeks after transplantation. Grayscale ultrasonography reveals a predominantly anechoic collection (open arrows) with thick septations medial to the left liver lobe. This collection was drained, and it was consistent with an infected biloma/abscess.

or embolism [49]. Liver enzymes may be markedly elevated [50]. A wedge-shaped, ill-defined, hypoechoic region is the typical appearance (Fig. 20) [49]. More diffuse and heterogeneous involvement can be observed in patients with systemic hypoperfusion or shock liver.

\section{Passive hepatic congestion}

Passive hepatic congestion due to right heart failure may cause elevated liver enzymes. In the acute phase, hepatomegaly, heterogeneous liver parenchyma, and ascites are common US findings associated with dilatation of the IVC and hepatic veins (Fig. 21) [51]. Chronic high hepatic venous pressure may eventually lead to hepatocyte death, fibrosis, and cirrhosis.

\section{Budd-Chiari syndrome}

Budd-Chiari syndrome is the result of partial or complete thrombosis or obstruction of the hepatic veins or IVC [52]. Heterogeneous and mottled liver parenchyma, hepatomegaly, and ascites are the commonly encountered grayscale US findings in an acute presentation to the ED (Fig. 22) [52]. Absent or reversed flow in the affected hepatic veins and IVC, as well as intrahepatic collaterals, can be observed on color Doppler [53].

\section{Transplantation-Related Vascular Conditions Hepatic artery stenosis/thrombosis}

Hepatic artery thrombosis is the most common early vascular complication after liver transplantation [54]. The hepatic artery supplies the biliary tree, and its occlusion may cause bile duct ischemia, eventually leading to biliary necrosis, bile leak, biloma, abscess, sepsis, and hepatic parenchymal infarct. In arterial occlusion, no flow or tardus-parvus waveform due to collateral flow is detected in the hepatic arteries (Fig. 23) [55]. 


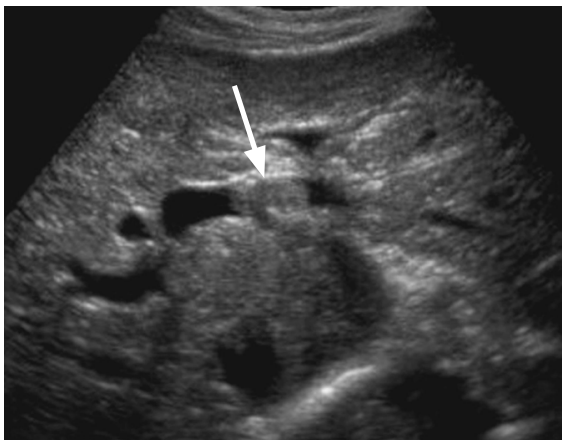

A

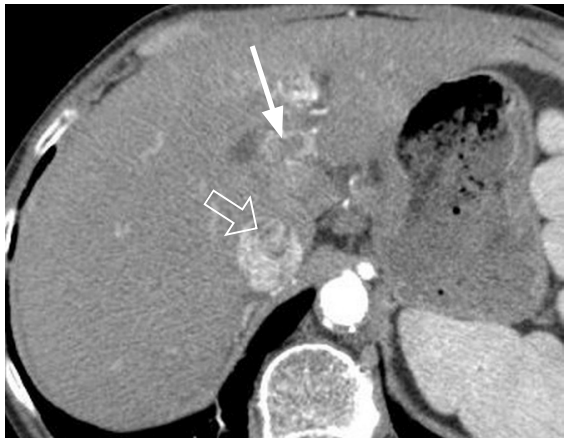

D

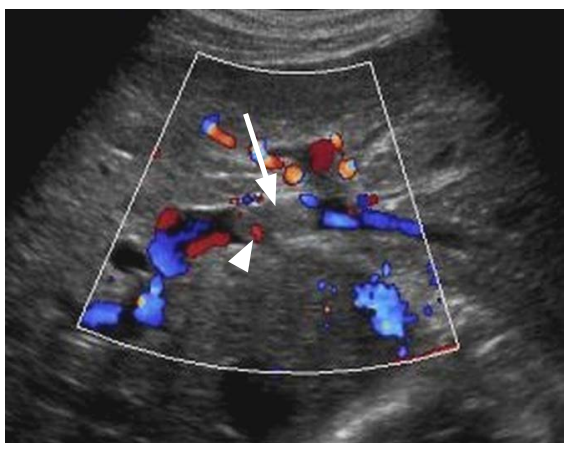

B

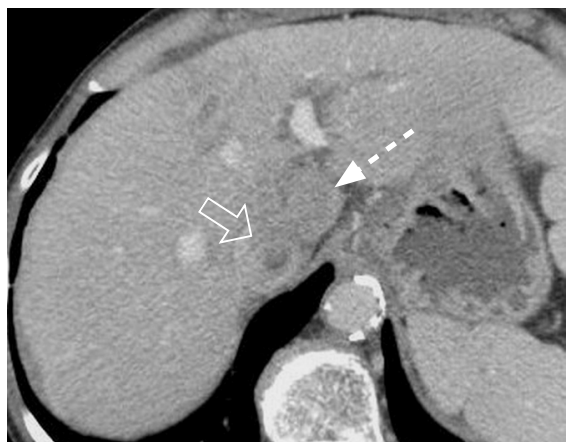

$\mathrm{E}$

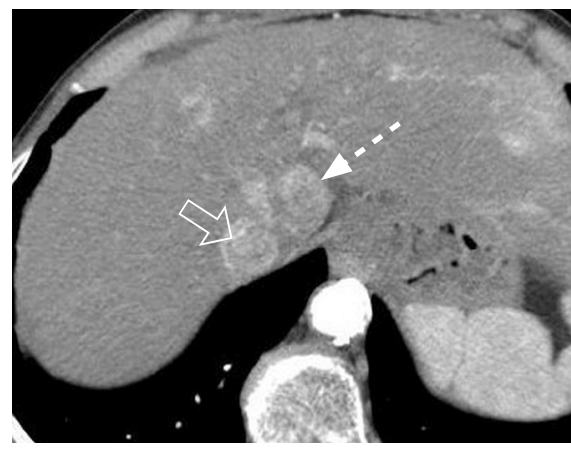

C

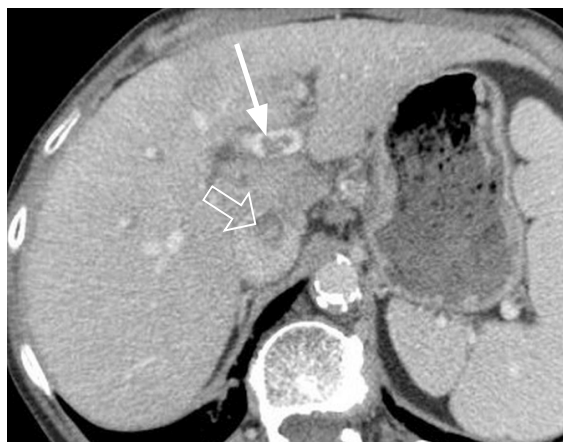

$\mathrm{F}$

Fig. 18. Portal vein tumor thrombus: a 64-year-old male patient with right upper quadrant pain and abnormal liver function tests.

A. Grayscale ultrasonography shows an echogenic thrombus in the left portal vein (arrow). B. Color Doppler ultrasonography reveals vascularity (arrowhead) within the thrombus (arrow). C-F. Contrast-enhanced computed tomography in the arterial phase (C, D) and portal venous phase ( $E, F)$ shows an arterially enhancing lesion (dashed arrows) in the caudate lobe with washout on the portal venous phase, enhancing portal vein tumor thrombus (arrows), and enhancing thrombus within the inferior vena cava (IVC) (open arrows). The constellation of the findings is consistent with hepatocellular carcinoma tumor thrombus in the left portal vein and IVC.

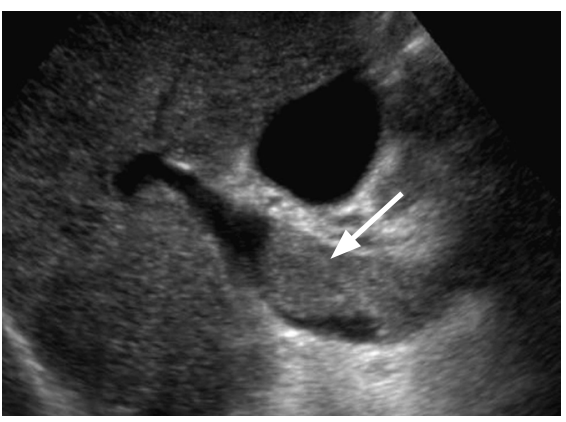

A

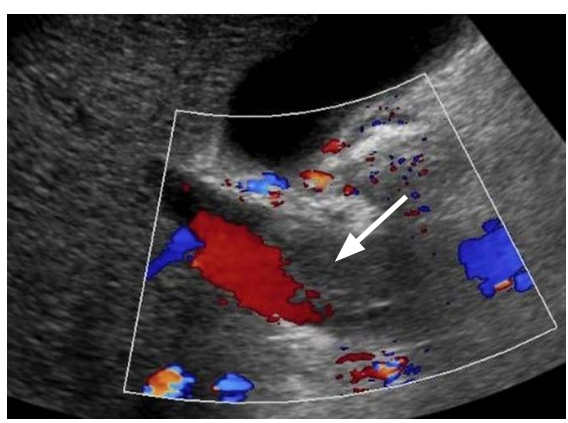

B

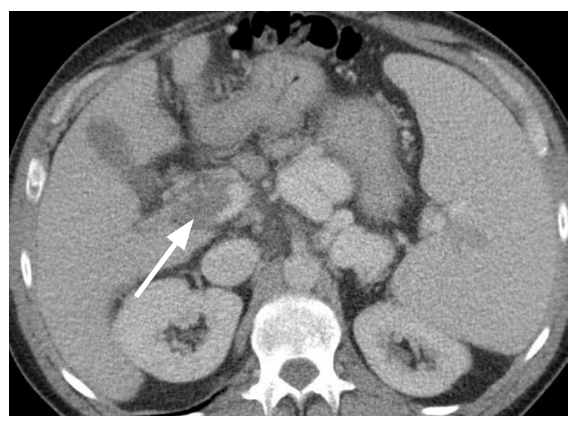

C

Fig. 19. Bland portal vein thrombosis: a 62-year-old man with right upper quadrant pain and abnormal liver function tests.

A, B. Grayscale (A) and color Doppler (B) ultrasonography reveal a slightly echogenic filling defect (arrows) in the main portal vein, consistent with portal vein thrombosis. There is no vascularity within the thrombus. C. An axial contrast-enhanced computed tomography shows a hypodense thrombus (arrow) within the main portal vein. There is also marked splenomegaly and dilated varicose splenic vein, consistent with portal hypertension.

The incidence of hepatic artery stenosis is about $11 \%$ after liver transplantation, and the anastomosis is the most common site of stenosis [56]. Color Doppler imaging reveals aliasing at the site of stenosis. On spectral imaging, the arterial waveform may show spectral broadening and increased peak systolic velocity $(>200 \mathrm{~cm} / \mathrm{s}$ ) $[57,58]$. Downstream low $(<0.5)$ resistive indices, the tardus-parvus phenomenon, and prolonged acceleration time ( $\geq 0.08$ seconds) may be seen when interrogating the intrahepatic arteries (Fig. 24). 


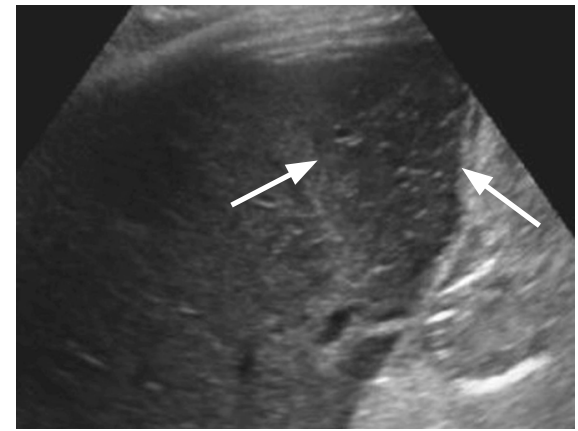

A

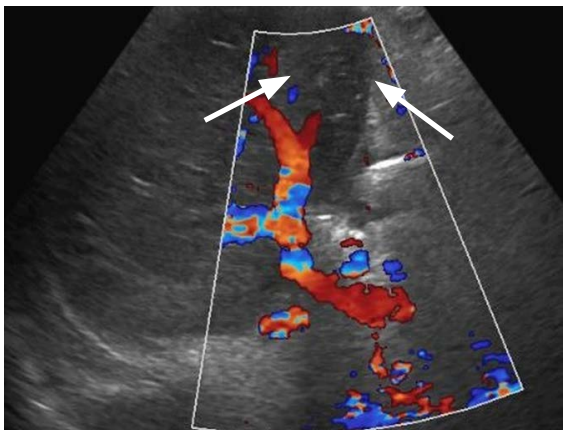

B

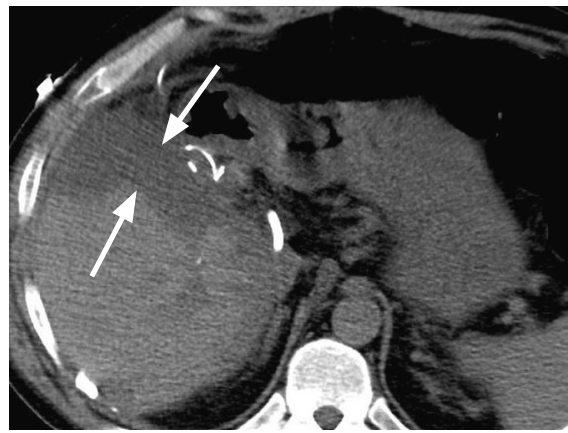

C

Fig. 20. Hepatic infarct: a 57-year-old man with a history of live donor liver transplant complicated by right hepatic artery perioperative dissection and subsequent ligation.

A, B. Grayscale (A) and color Doppler (B) ultrasonography show a wedge-like, avascular hypoechoic area (arrows) in the medial aspect of the liver. C. An axial non-contrast computed tomography from the upper abdomen shows extensive necrosis in the medial liver corresponding to the hypoechoic area shown on ultrasonography (arrows).

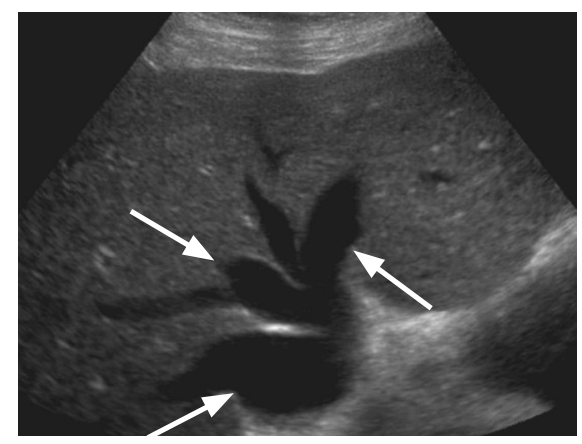

A

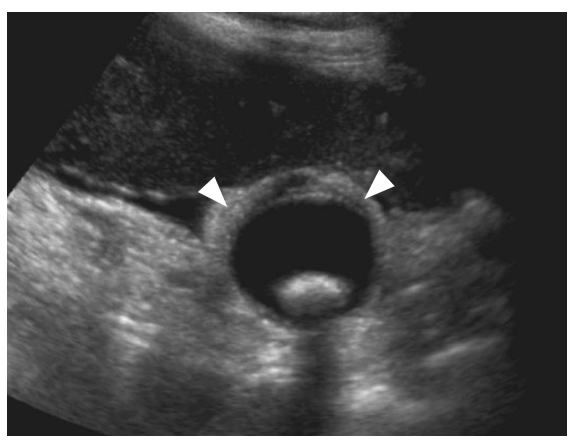

B

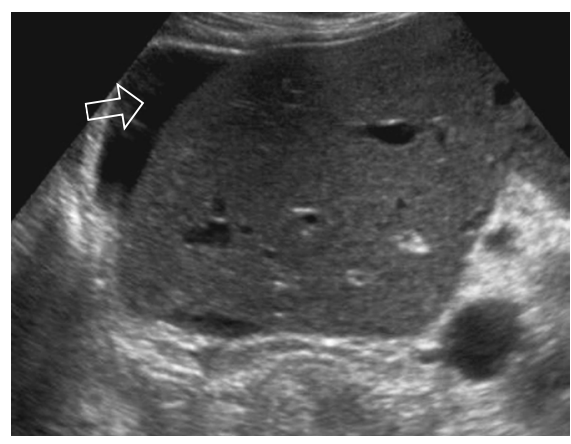

C

Fig. 21. Passive hepatic congestion: a 72-year-old man with a history of congestive heart failure presented with shortness of breath, abdominal pain, and abnormal liver function tests.

A-C. Grayscale ultrasonography shows dilated inferior vena cava and hepatic veins (arrows), gallbladder wall edema (arrowheads), and ascites (open arrow). The degree of venous dilatation may correlate with the severity of heart failure.

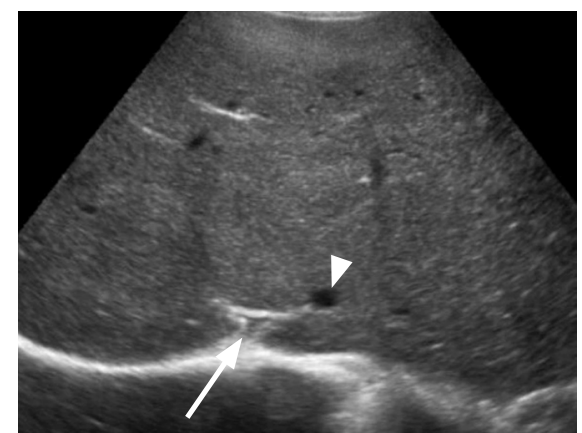

A

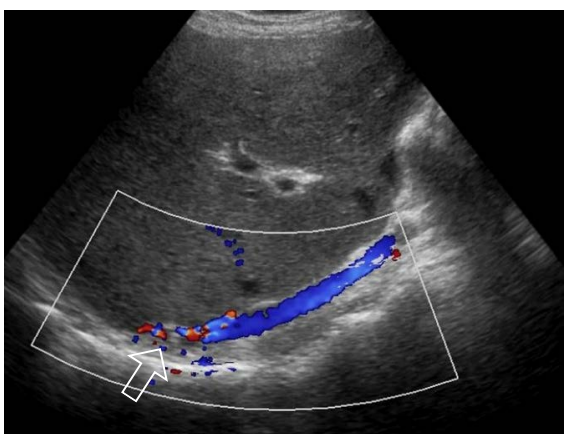

B

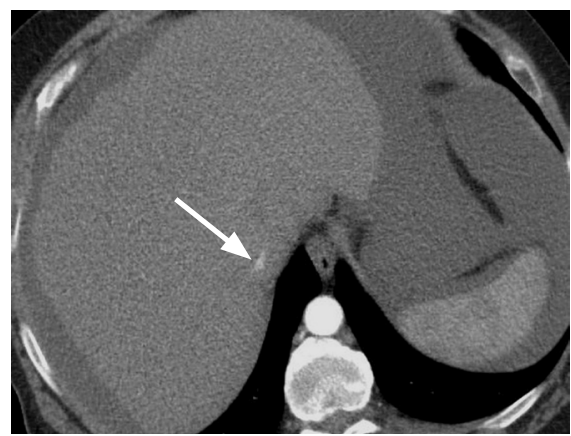

C

Fig. 22. Budd-Chiari syndrome: a 35-year-old man with a past medical history of nonalcoholic steatohepatitis cirrhosis presented with right upper quadrant pain and abnormal liver function tests.

A, B. Grayscale (A) and color Doppler (B) ultrasonography demonstrate narrowing (arrow) of the intrahepatic segment of the inferior vena cava (IVC) with aliasing artifact (open arrow), consistent with stenosis. A prominent venous collateral is present adjacent to the IVC stenosis (arrowhead). C. Contrast-enhanced axial computed tomography shows narrowing of the intrahepatic IVC (arrow). Selective catheter angiography (not shown) of the hepatic veins and IVC confirmed the diagnosis of Budd-Chiari Syndrome. 


\section{Portal vein thrombosis}

Post-transplant PVT is a relatively rare complication $(1 \%-2 \%$ of cases) [59]. It manifests as diminished or absent intraluminal flow on color Doppler US with variable echogenicity of the thrombus itself (Fig. 25).

\section{Portal vein stenosis}

Post-transplant portal vein stenosis is more common and appears as a focal narrowing of the portal vein, usually at the anastomosis. It should be noted that the portal vein caliber may normally be mildly narrowed at the anastomosis, which should not be confused with true stenosis [60]. Turbulent flow on spectral Doppler US manifests as aliasing and spectral broadening (Fig. 26). The flow velocity is increased at the level of stenosis relative to the pre-stenotic segment (often three to four-fold). Post-stenotic portal vein dilatation, hilar venous collaterals, and other secondary signs of portal hypertension may develop.

\section{Hepatic vein thrombosis/stenosis}

The most common site of hepatic vein stenosis or thrombosis is the venous anastomosis at the IVC; it manifests as aliasing or a lack of blood flow on color Doppler US. An intraluminal thrombus, focal stricture, or pre-stenotic dilatation can be observed. Monophasic waveforms and spectral broadening with increased velocity are the

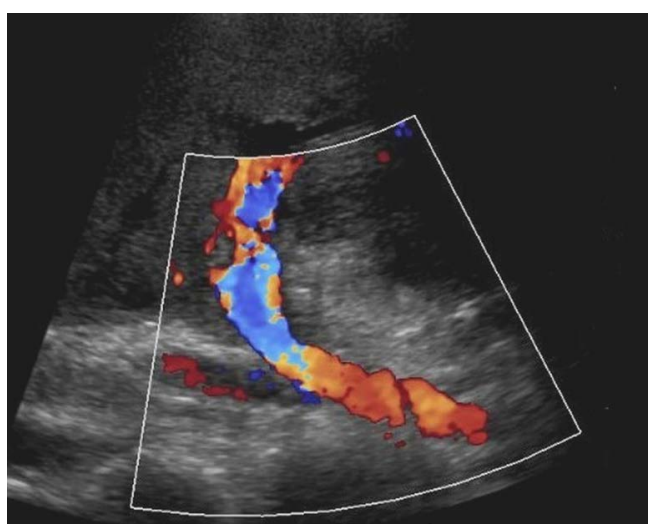

A

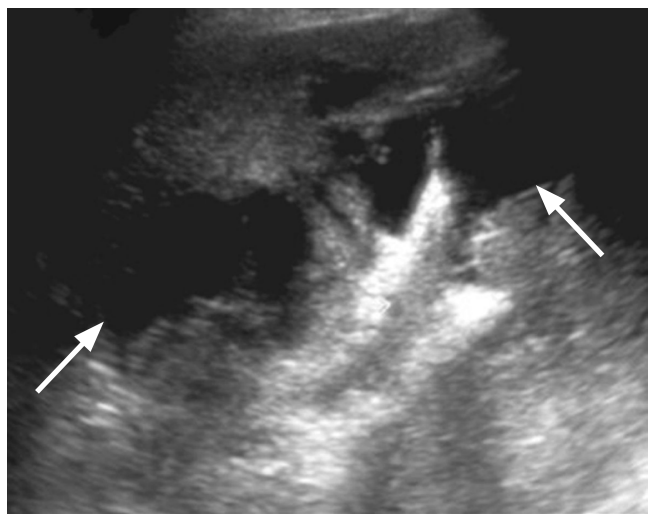

C

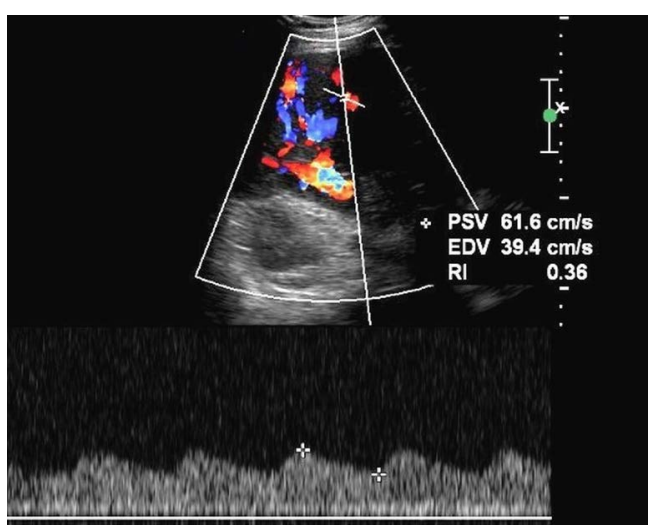

B

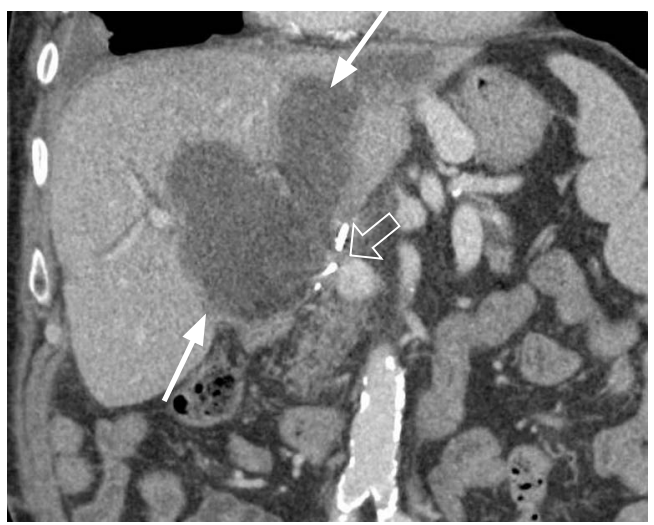

D

Fig. 23. Post-transplant hepatic artery thrombosis with secondary biliary necrosis and biloma formation: a 52-year-old woman with a history of liver transplantation 2 months ago presented with jaundice and abnormal liver function tests.

A. Color Doppler ultrasonography shows no hepatic artery flow at the portal hilum. B. Spectral Doppler ultrasonography of a parenchymal branch of the right hepatic artery shows a prolonged systolic acceleration time and decreased systolic amplitude, compatible with a tardus-parvus waveform. C. Grayscale ultrasonography shows a large thick-walled hypoechoic collection in the portal hilum (arrows). D. Coronal contrastenhanced computed tomography demonstrates a large, irregular, hypodense hepatic collection (arrows). The hepatic artery is thrombosed at the anastomosis (open arrow). The collection was drained, and it was consistent with an infected biloma. Catheter angiography (not shown) demonstrated no opacification/flow through the expected location of the hepatic artery, compatible with occlusion. Associated collateral hepatic parenchymal supply arising from hypertrophied branches of the right phrenic and right internal mammary arteries was found during catheter angiography. 


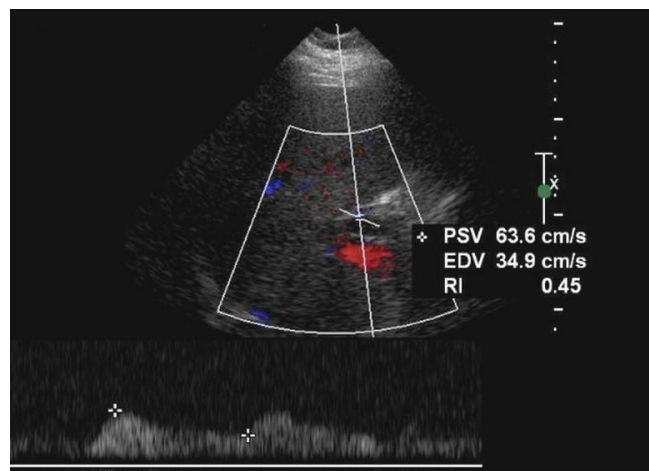

A

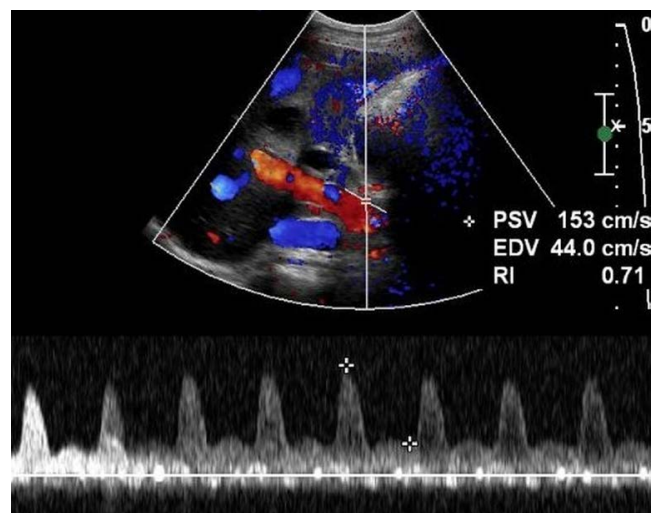

C

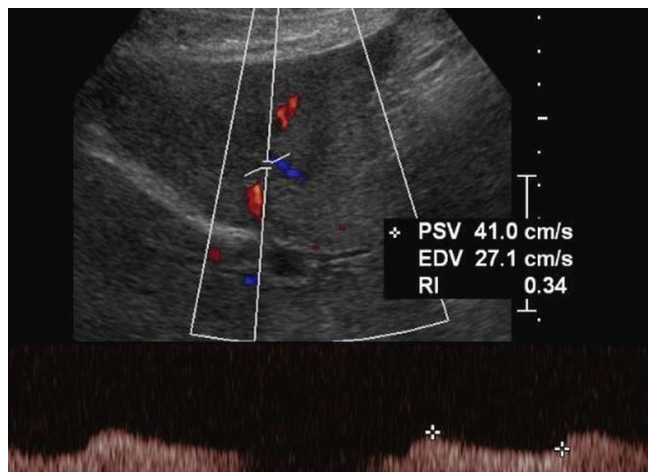

B

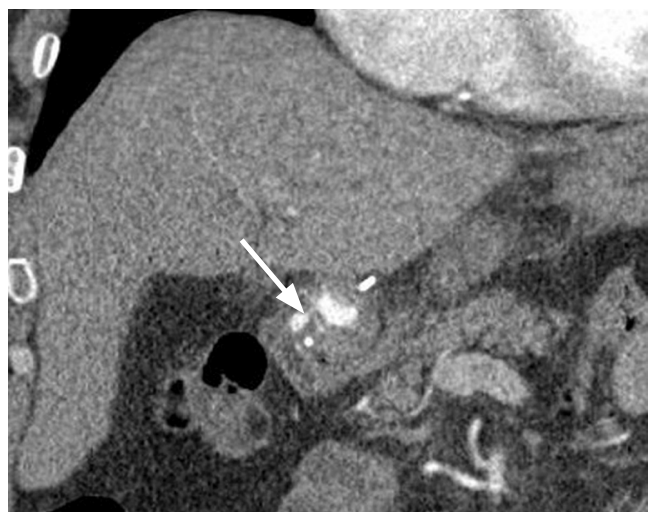

D

Fig. 24. Post-transplant hepatic artery stenosis: a 53-year-old man with a past medical history of liver transplantation 1 year ago presented with nausea, vomiting, abdominal discomfort, and abnormal liver function tests.

A, B. Spectral Doppler ultrasonography shows patent right (A) and left (B) hepatic arteries with decreased systolic amplitude, prolonged acceleration times, and tardus-parvus waveforms, suggesting proximal hepatic arterial stenosis. C. Spectral Doppler ultrasonography from the main hepatic artery at the anastomosis level shows an increased velocity of the proper hepatic artery. D. Contrast-enhanced coronal computed tomography shows severe focal narrowing (arrow) at the hepatic artery anastomosis, consistent with stenosis.

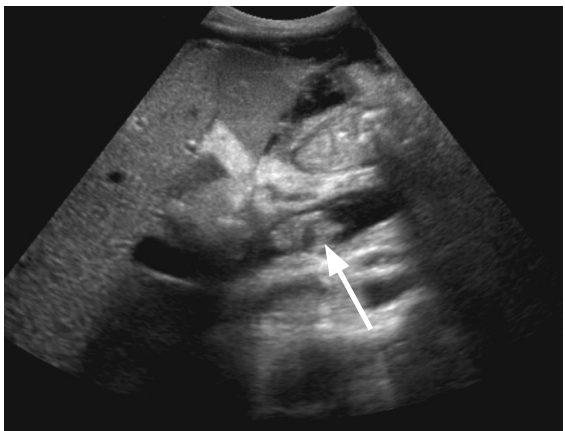

A

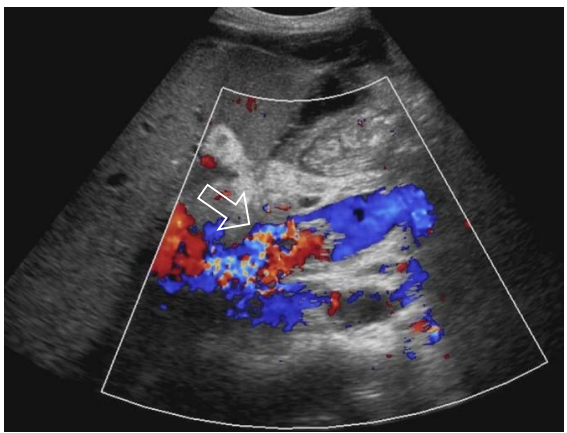

B

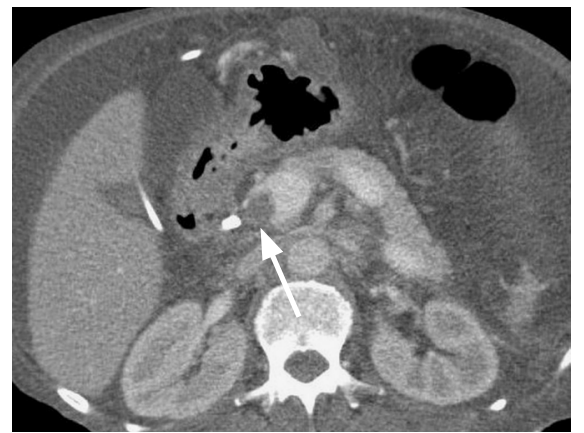

C

Fig. 25. Post-transplant portal vein thrombosis: a 51-year-old man, status post-liver transplantation 1 month ago, presented with abdominal pain and fatigue.

A, B. Grayscale (A) and color Doppler (B) ultrasonography reveal a partially occlusive echogenic thrombus (arrow) within the main portal vein with adjacent color aliasing (open arrow). C. Contrast-enhanced axial computed tomography confirms the presence of a hypodense thrombus (arrow) within the main portal vein. Large-volume ascites is also present. 


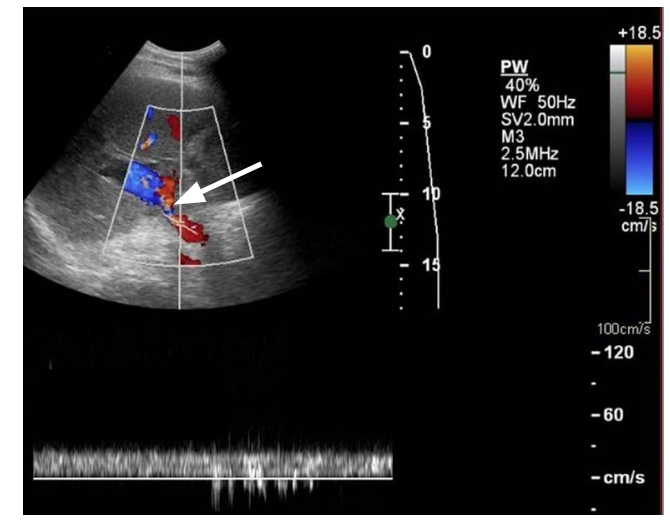

A

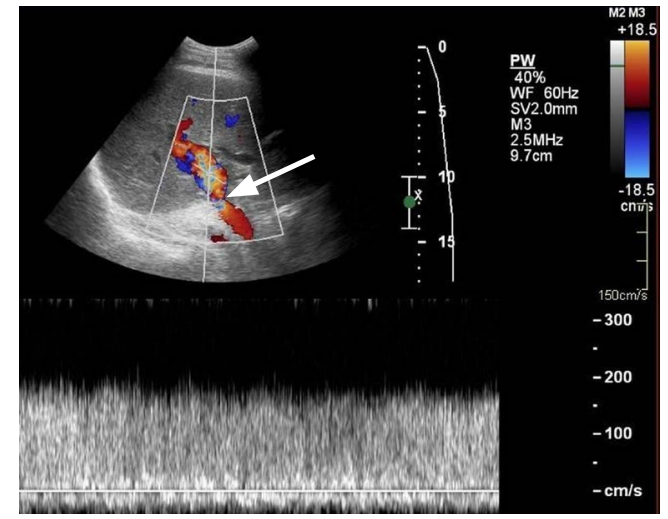

B

Fig. 26. Post-transplant portal vein stenosis: a 73-yearold man, status post-liver transplantation, presented with fatigue and abnormal liver function tests.

A, B. Spectral Doppler ultrasonography shows a main portal vein velocity of $35 \mathrm{~cm} / \mathrm{s}$ preanastomosis $(A)$ and $177 \mathrm{~cm} / \mathrm{s}$ just beyond the anastomosis (B). The findings are consistent with stenosis at the anastomosis level (arrows).

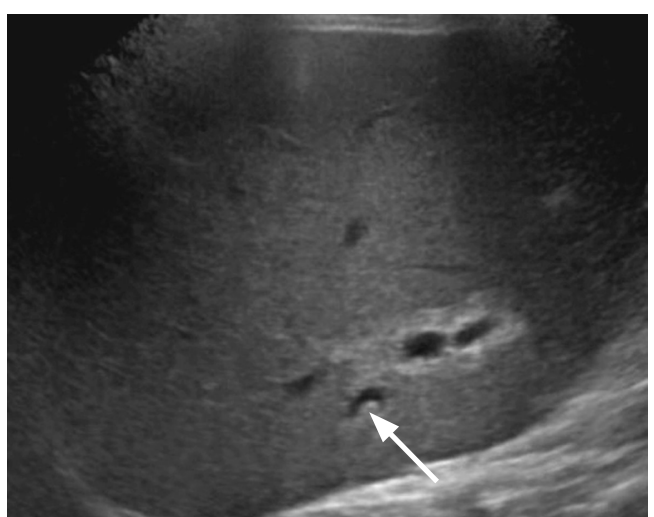

A

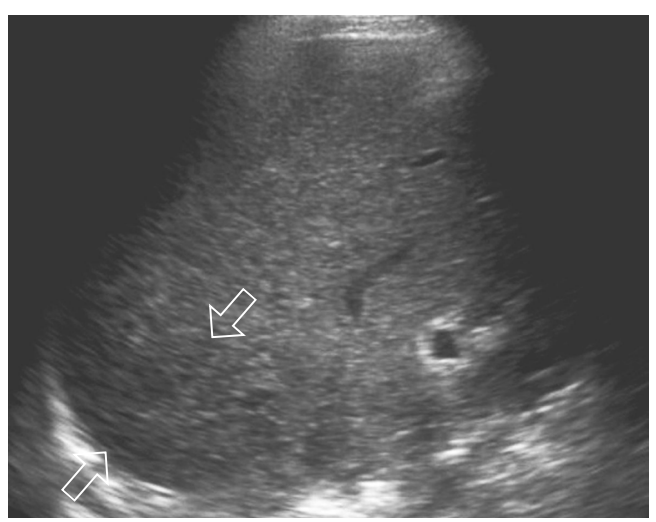

C

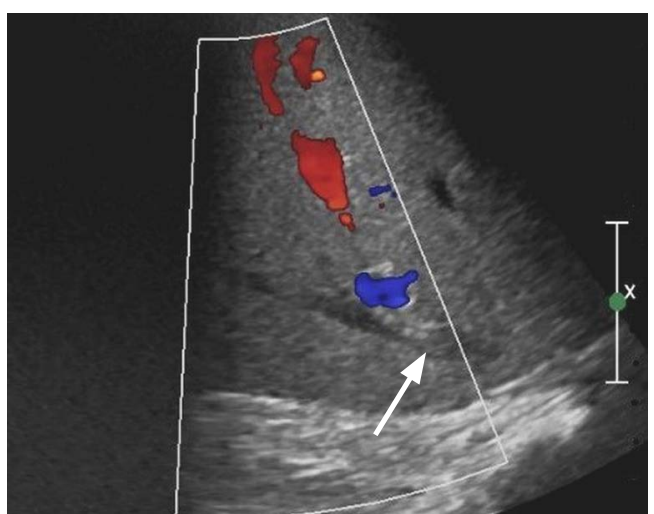

B

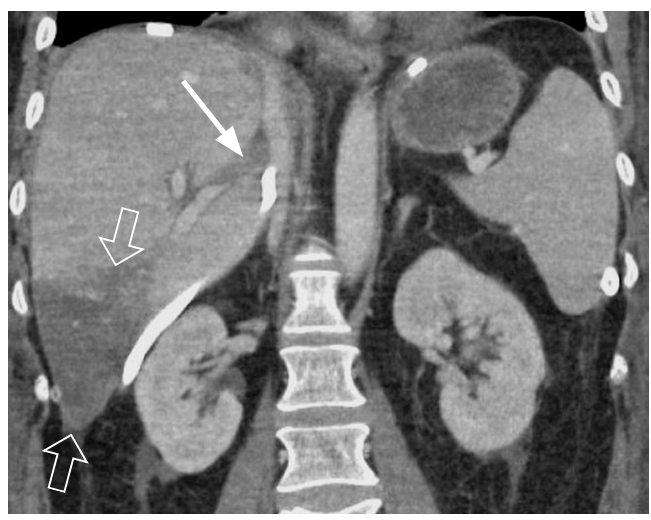

D

Fig. 27. Post-transplant hepatic vein stenosis: a 56-year-old woman status post-living donor liver transplantation 10 days previously with persistently increased liver function tests.

A, B. Grayscale (A) and color Doppler (B) ultrasonography show an echogenic, occlusive thrombus (arrows) in an accessory right inferior hepatic vein. There is no flow in the lumen on color Doppler imaging. C. Transverse grayscale ultrasonography shows a hypoechoic region (open arrows) in segment 6 that indicates a hepatic infarct due to venous outflow obstruction. D. Coronal contrast-enhanced computed tomography demonstrates an occlusive thrombus (arrow) in the accessory right inferior hepatic vein and congested hepatic parenchyma (open arrows) in segment 6 . These findings were confirmed via exploratory laparotomy. 
findings on spectral Doppler imaging (Fig. 27).

\section{Conclusion}

With its wide availability and practicality, US remains the initial modality of choice in evaluating abnormal LFTs in the ED. In conjunction with the patient's pertinent history and LFT levels, US may accurately diagnose many common diseases and can be used as a major problem-solver in the ED. An organized approach by the radiologist is crucial in formulating the correct differential diagnosis and determining the appropriate next clinical or imaging step for the patient.

Conflict of interest statement: The authors have no financial relationship with a commercial organization that may have a direct or indirect interest in the content.

ORCID: Baran Umut Vardar: https://orcid.org/0000-0003-1058-847X; Carolyn S. Dupuis: https://orcid.org/0000-0003-4336-2573; Alan J. Goldstein: https://orcid.org/0000-00015974-917X; Zeynep Vardar: https://orcid.org/0000-0002-7510-9524; Young H. Kim: https://orcid.org/0000-0003-1095-2892

\section{Author Contributions}

Conceptualization: Vardar BU, Dupuis CS, Goldstein AJ, Kim YH. Data acquisition: Vardar BU, Vardar Z, Kim YH. Data analysis or interpretation: Vardar BU, Dupuis CS, Goldstein AJ, Vardar Z, Kim YH. Drafting of the manuscript: Vardar BU, Dupuis CS, Kim YH. Critical revision of the manuscript: Vardar BU, Dupuis CS, Goldstein AJ, Kim YH. Approval of the final version of the manuscript: all authors.

\section{Conflict of Interest}

No potential conflict of interest relevant to this article was reported.

\section{References}

1. Radcke S, Dillon JF, Murray AL. A systematic review of the prevalence of mildly abnormal liver function tests and associated health outcomes. Eur I Gastroenterol Hepatol 2015;27:1-7.

2. Sulava E, Bergin S, Long B, Koyfman A. Elevated liver enzymes: emergency department-focused management. J Emerg Med 2017:52:654-667.

3. Giannini EG, Testa R, Savarino V. Liver enzyme alteration: a guide for clinicians. CMAJ 2005;172:367-379.

4. Spence SC, Teichgraeber D, Chandrasekhar C. Emergent right upper quadrant sonography. J Ultrasound Med 2009;28:479-496.

5. Expert Panel on Gastrointestinal Imaging; Peterson CM, McNamara MM, Kamel IR, Al-Refaie WB, Arif-Tiwari H, et al. ACR Appropriateness Criteria ${ }^{\circledR}$ right upper quadrant pain. J Am Coll
Radiol 2019;16(5S):S235-S243.

6. Yokoe M, Hata J, Takada T, Strasberg SM, Asbun HJ, Wakabayashi G, et al. Tokyo Guidelines 2018: diagnostic criteria and severity grading of acute cholecystitis (with videos). J Hepatobiliary Pancreat Sci 2018;25:41-54.

7. Kiewiet JJ, Leeuwenburgh MM, Bipat S, Bossuyt PM, Stoker J, Boermeester MA. A systematic review and meta-analysis of diagnostic performance of imaging in acute cholecystitis. Radiology 2012;264:708-720.

8. Yarmenitis SD. Ultrasound of the gallbladder and the biliary tree. Eur Radiol 2002;12:270-282.

9. Fadahunsi 00 , Ibitoye BO, Adisa AO, Alatise OI, Adetiloye VA, Idowu BM. Diagnostic accuracy of ultrasonography in adults with obstructive jaundice. J Ultrason 2020;20:e100-e105.

10. Kumar M, Prashad R, Kumar A, Sharma R, Acharya SK, Chattopadhyay TK. Relative merits of ultrasonography, computed tomography and cholangiography in patients of surgical obstructive jaundice. Hepatogastroenterology 1998;45:2027-2032.

11. ASGE Standards of Practice Committee; Maple JT, Ben-Menachem $\mathrm{T}$, Anderson MA, Appalaneni V, Banerjee $\mathrm{S}$, et al. The role of endoscopy in the evaluation of suspected choledocholithiasis. Gastrointest Endosc 2010;71:1-9.

12. Ortega D, Burns PN, Hope Simpson D, Wilson SR. Tissue harmonic imaging: is it a benefit for bile duct sonography? AJR Am J Roentgenol 2001;176:653-659.

13. Kubota K, Hisa N, Nishikawa T, Ohnishi T, Ogawa Y, Yoshida S. The utility of tissue harmonic imaging in the liver: a comparison with conventional gray-scale sonography. Oncol Rep 2000;7:767-771.

14. Skoczylas K, Pawelas A. Ultrasound imaging of the liver and bile ducts: expectations of a clinician. J Ultrason 2015;15:292-306.

15. Conrad MR, Landay MJ, Janes JO. Sonographic "parallel channel" sign of biliary tree enlargement in mild to moderate obstructive jaundice. AJR Am J Roentgenol 1978;130:279-286.

16. Indiran V, Kokilavani J. Double-barrel shotgun sign. Abdom Radiol (NY) 2019:44:1197-1198.

17. Rumack CM, Levin D. Diagnostic ultrasound. 5th ed. Philadelphia, PA: Elsevier, 2018;167-168.

18. Zahedi-Nejad N, Narouei S, Fahimy F. Common bile duct (CBD) diameter in opium-addicted men: comparison with non-addict controls. Pol J Radiol 2010;75:20-24.

19. Park SM, Kim WS, Bae IH, Kim JH, Ryu DH, Jang LC, et al. Common bile duct dilatation after cholecystectomy: a one-year prospective study. J Korean Surg Soc 2012;83:97-101.

20. Bistritz L, Bain VG. Sphincter of Oddi dysfunction: managing the patient with chronic biliary pain. World J Gastroentero 2006;12:3793-3802.

21. Bachar GN, Cohen M, Belenky A, Atar E, Gideon S. Effect of aging on the adult extrahepatic bile duct: a sonographic study. J Ultrasound Med 2003;22:879-882. 
22. Kaim A, Steinke K, Frank M, Enriquez R, Kirsch E, Bongartz G, et al. Diameter of the common bile duct in the elderly patient: measurement by ultrasound. Eur Radiol 1998;8:1413-1415.

23. Lee JM, Boll DT. Disease of the gallbladder and biliary tree. In: Hodler J, Kubik-Huch RA, von Schulthess GK, eds. Diseases of the abdomen and pelvis 2018-2021: diagnostic imaging - IDKD book. Cham: Springer, 2018;49-56.

24. Alkarboly TA, Fatih SM, Hussein HA, Ali TM, Faraj HI. The accuracy of transabdominal ultrasound in detection of the common bile duct stone as compared to endoscopic retrograde cholangiopancreatography (with literature review). Open J Gastroenterol 2016:275-299.

25. Varghese JC, Liddell RP, Farrell MA, Murray FE, Osborne $\mathrm{DH}$, Lee MJ. Diagnostic accuracy of magnetic resonance cholangiopancreatography and ultrasound compared with direct cholangiography in the detection of choledocholithiasis. Clin Radiol 2000;55:25-35.

26. Surlin V, Saftoiu A, Dumitrescu D. Imaging tests for accurate diagnosis of acute biliary pancreatitis. World J Gastroenterol 2014;20:16544-16549.

27. Baron RL, Tublin ME, Peterson MS. Imaging the spectrum of biliary tract disease. Radiol Clin North Am 2002;40:1325-1354.

28. Shanmugam V, Beattie GC, Yule SR, Reid W, Loudon MA. Is magnetic resonance cholangiopancreatography the new gold standard in biliary imaging? Br J Radiol 2005;78:888-893.

29. Williams E, Beckingham I, El Sayed G, Gurusamy K, Sturgess $R$, Webster $G$, et al. Updated guideline on the management of common bile duct stones (CBDS). Gut 2017;66:765-782.

30. Hunt DR. Common bile duct stones in non-dilated bile ducts?: an ultrasound study. Australas Radiol 1996;40:221-222.

31. Singh A, Gelrud A, Agarwal B. Biliary strictures: diagnostic considerations and approach. Gastroenterol Rep (Oxf) 2015;3:2231.

32. Kloek JJ, van Delden OM, Erdogan D, ten Kate FJ, Rauws EA, Busch $\mathrm{OR}$, et al. Differentiation of malignant and benign proximal bile duct strictures: the diagnostic dilemma. World J Gastroenterol 2008; 14:5032-5038.

33. Dorrell R, Pawa S, Zhou Y, Lalwani N, Pawa R. The diagnostic dilemma of malignant biliary strictures. Diagnostics (Basel) 2020;10:337.

34. Joo I, Lee JM, Yoon JH. Imaging diagnosis of intrahepatic and perihilar cholangiocarcinoma: recent advances and challenges. Radiology 2018;288:7-13.

35. Yu J, Turner MA, Fulcher AS, Halvorsen RA. Congenital anomalies and normal variants of the pancreaticobiliary tract and the pancreas in adults: part 1, Biliary tract. AJR Am J Roentgenol 2006;187:1536-1543.

36. Banks JS, Saigal G, D'Alonzo JM, Bastos MD, Nguyen NV. Choledochal malformations: surgical implications of radiologic findings. AJR Am J Roentgenol 2018;210:748-760.

37. Hamer OW, Aguirre DA, Casola G, Lavine JE, Woenckhaus M, Sirlin CB. Fatty liver: imaging patterns and pitfalls. Radiographics 2006;26:1637-1653.

38. Kutaiba N, Rotella JA, Ardalan Z, Testro A. Incidental hepatic steatosis in radiology reports: a survey of emergency department clinicians' perspectives and current practice. J Med Imaging Radiat Oncol 2019;63:573-579.

39. Obika M, Noguchi H. Diagnosis and evaluation of nonalcoholic fatty liver disease. Exp Diabetes Res 2012;2012:145754.

40. Ferraioli G, Soares Monteiro LB. Ultrasound-based techniques for the diagnosis of liver steatosis. World J Gastroenterol 2019;25:6053-6062.

41. Patel NJ, Caserta MP, DiSantis DJ. The "starry sky" liver. Abdom Radiol (NY) 2017;42:328-329.

42. Iranpour P, Lall C, Houshyar R, Helmy M, Yang A, Choi Jl, et al. Altered Doppler flow patterns in cirrhosis patients: an overview. Ultrasonography 2016;35:3-12.

43. Sanyal AJ, Yoon SK, Lencioni R. The etiology of hepatocellular carcinoma and consequences for treatment. Oncologist 2010;15 Suppl 4:14-22.

44. Buettner S, van Vugt JL, IJzermans JN, Groot Koerkamp B. Intrahepatic cholangiocarcinoma: current perspectives. Onco Targets Ther 2017;10:1131-1142.

45. Konstantinidis IT, Mastrodomenico P, Sofocleous CT, Brown KT, Getrajdman GI, Gonen M, et al. Symptomatic perihepatic fluid collections after hepatic resection in the modern era. J Gastrointest Surg 2016;20:748-756.

46. Intagliata NM, Caldwell SH, Tripodi A. Diagnosis, development, and treatment of portal vein thrombosis in patients with and without cirrhosis. Gastroenterology 2019;156:1582-1599.

47. Jha RC, Khera SS, Kalaria AD. Portal vein thrombosis: imaging the spectrum of disease with an emphasis on MRI features. AJR Am J Roentgenol 2018;211:14-24.

48. Quencer KB, Friedman T, Sheth R, Oklu R. Tumor thrombus: incidence, imaging, prognosis and treatment. Cardiovasc Diagn Ther 2017;7(Suppl 3):S165-S177.

49. Whang G, Chopra S, Tchelepi H. "Bright band sign": a grayscale ultrasound finding in hepatic infarction. J Ultrasound Med 2019;38:2515-2520.

50. Lightsey JM, Rockey DC. Current concepts in ischemic hepatitis. Curr Opin Gastroenterol 2017;33:158-163.

51. Hokama A, Arakaki S, Shibata D, Maeshiro T, Kinjo F, Fujita J. "Playboy bunny" sign of congestive heart failure. West J Emerg Med 2011;12:433-434.

52. Elsayes KM, Shaaban AM, Rothan SM, Javadi S, Madrazo BL, Castillo RP, et al. A comprehensive approach to hepatic vascular disease. Radiographics 2017;37:813-836.

53. Millener P, Grant EG, Rose S, Duerinckx A, Schiller VL, Tessler 
FN, et al. Color Doppler imaging findings in patients with BuddChiari syndrome: correlation with venographic findings. AJR Am J Roentgenol 1993;161:307-312.

54. Piardi T, Lhuaire M, Bruno O, Memeo R, Pessaux P, Kianmanesh $R$, et al. Vascular complications following liver transplantation: a literature review of advances in 2015. World J Hepatol 2016;8:3657.

55. Dydynski PB, Bluth El, Altmeyer W, Devun DA, Milburn JM. Collateral transformation of the hepatic artery after liver transplantation. AJR Am J Roentgenol 2008;191:546-549.

56. Di Martino M, Rossi M, Mennini G, Melandro F, Anzidei M, De Vizio $\mathrm{S}$, et al. Imaging follow-up after liver transplantation. Br J Radiol 2016;89:20151025.

57. Dodd GD 3rd, Memel DS, Zajko AB, Baron RL, Santaguida LA.
Hepatic artery stenosis and thrombosis in transplant recipients: Doppler diagnosis with resistive index and systolic acceleration time. Radiology 1994;192:657-661.

58. Low G, Crockett AM, Leung K, Walji AH, Patel VH, Shapiro AM, et al. Imaging of vascular complications and their consequences following transplantation in the abdomen. Radiographics 2013;33:633-652.

59. Caiado AH, Blasbalg R, Marcelino AS, da Cunha Pinho M, Chammas MC, da Costa Leite C, et al. Complications of liver transplantation: multimodality imaging approach. Radiographics 2007;27:14011417.

60. Garcia-Criado A, Gilabert R, Bargallo X, Bru C. Radiology in liver transplantation. Semin Ultrasound CT MR 2002;23:114-129. 